\title{
QUELQUES ASPECTS NOUVEAUX DU MÉTABOLISME DE L'AZOTE CHEZ LE PORG ET LEURS CONSÉQUENCES POUR LA SATISFACTION DE SES BESOINS EN PROTÉINES
}

\author{
G. FAUCONNEAU et R. PION \\ Station d'Études des Métabolismes, \\ Centre de Recherches de Clermont-Ferrand, I. N. R. A., \\ 62 - Saint-Genès-Champanelle
}

\begin{abstract}
RÉSUMÉ
\end{abstract}
Nous avons passé en revue différents facteurs de la nutrition azotée du porc en croissance.

Croissance et besoins en protéines et en acides aminés (tabl. I-6)

Le corps du porcelet nouveau-né contient seulement i I p. Ioo de protéines et 6 p. Ioo de lipides. Ces teneurs sont respectivement de $15 \mathrm{p}$. Ioo et de i6 p. Ioo après deux semaines. La synthèse protéique nette journalière augmente régulièrement, pour atteindre Ioo- $125 \mathrm{~g}$ chez des porcs de 30 à $35 \mathrm{~kg}$; elle reste ensuite constante chez les porcs plus âgés, alors que la synthèse de lipides continue à augmenter, et cela d'autant plus que le niveau d'alimentation est plus élevé. La synthèse des protéines n'est pas diminuée par une restriction calorique n'excédant pas $\mathrm{I}_{5}$ à 20 p. roo du besoin. Le rapport protéines fixées/énergie métabolisable reste constant jusqu'à un poids vif de 35 à $40 \mathrm{~kg}$, puis diminue régulièrement lorsque l'animal poursuit sa croissance. Le rapport protéines/énergie métabolisable (ou protéines/énergie digestible) de la ration doit donc être constant dans la première phase, puis diminuer régulièrement avec l'âge de l'animal dans la deuxième.

Les besoins ne varient pas dans les mêmes proportions pour tous les acides aminés indispensables au cours de la croissance. Le besoin journalier de lysine augmente rapidement jusqu'à $40 \mathrm{~kg}$ de poids vif, puis plus lentement ensuite. L'augmentation ne correspond plus dans la deuxième période qu'à une augmentation du besoin d'entretien. Au contraire, le besoin en méthionine augmente plus avec l'âge que la moyenne des besoins en acides aminés (tabl. 6).

\footnotetext{
* Rapport présenté aux commissions de la Fédération Européenne de Zootechnie, Helsinki, juin I969.
} 


\section{Acides aminés libres du sang et nutrition protéique (tabl. $7,8,9$ )}

Lcs acides aminés libres du sang constituent la principale forme de transport des produits de la digestion des protéines alimentaires vers les tissus qui les utiliseront à des synthèses protéiques. Leurs teneurs sont à chaque instant le résultat d'un équilibre entre les apports provenant du tube digestif, ou du catabolisme de protéines et les quantités utilisées par les tissus. C'est pourquoi des chercheurs ont essayé de relier les teneurs en acides aminés libres du sang de porc, à ses besoins en acides aminés et à la composition en acides aminés des aliments ingérés. Les valeurs moyennes obtenues dans différentes études sont généralement en accord, au moins en ce qui concerne les acides aminés indispensables (tabl 7). Il y a une interrelation entre les teneurs des différents acides aminés, mais les teneurs en acides aminés indispensables sont généralement en rapport avec la composition en acides aminés de la ration.

\section{Acides aminés libres du sang et digestion}

Les concentrations des différents acides aminés dans le sang porte dépendent de la cinétique de leurs apports par le tube digestif. Aussi avons-nous étudié les variations des teneurs en acides aminés libres du sang porte au cours de la digestion de divers aliments : farine de hareng, orge, tourteau d'arachide, aliment sans azote, blé et tournesol supplémentés ou non en lysine. Les augmentations des teneurs en acides aminés indispensables sont très élevées dans le cas de la farine de poisson et très faibles dans celui de l'orge. Elles sont importantes au cours de la digestion de l'arachide, sauf pour la lysine et la thréonine qui constituent les facteurs limitants de cet aliment protéique. La lysine ingérée sous forme libre semble être absorbée en même temps que celle qui provient de la digestion des protéines du blé ou du tournesol (tabl. ro, i I ; fig. I). Comme les variations de teneurs observées au cours de la digestion sont très importantes, leur détermination peut être très utile pour l'étude de la supplémentation protéine-acide aminé, et de la disponibilité de certains acides aminés.

\section{Valeur nutritive des protéines}

Les proportions des différents acides aminés des protéines alimentaires correspondent plus ou moins bien aux besoins des animaux (tabl. I2). Les compositions des différents aliments peuvent facilement être comparées entre elles, et aux besoins des animaux, en exprimant les teneurs des différents acides aminés indispensables et semi-indispensables en p. Ioo de leur somme. La réalisation de rations équilibrées est facilitée par l'amélioration de la composition de certaines protéines (maïs), et par l'utilisation d'acides aminés (DL-méthionine, L-lysine) et de protéines industrielles (levures, algues). Mais la disponibilité de certains acides aminés peut être diminuée au cours de la fabrication ou du stockage, et il est de plus en plus nécessaire de disposer d'une méthode précise de mesure de cette disponibilité.

\section{INTRODUCTION}

L'intensification de l'élevage du porc se traduit par certaines modifications des méthodes d'élevage traditionnelles. L'accroissement du nombre de portées produites chaque année par les truies nécessite le sevrage précoce des porcelets alors que la nutrition des truies pose moins de problèmes ; en effet, pendant la gestation, le rendement de l'énergie et de l'azote est excellent car l'anabolisme est favorisé par le complexe hormonal de gestation tandis que, pendant la lactation raccourcie, l'extériorisation des potentialités génétiques laitières est favorisée par l'utilisation des réserves mobilisables (protéines et lipides) de la mère, (SALMON-LEGAGNEUR, I965; LodGe, 1962). La nutrition azotée et énergétique des jeunes porcs dont la phase de synthèse protéique est importante et mal connue est donc un problème particulièrement important qui doit être étudié à la fois par des physiologistes, des nutritionnistes et des généticiens.

Nous examinerons successivement divers aspects de la nutrition azotée en rapport avec ce problème : les besoins en acides aminés indispensables et leur déterminisme, la composition en 
acides aminés libres du sang en relation avec l'état de nutrition azotée des animaux, et la valeur nutritive des protéines dont la composition en acides aminés indispensables est à peu près connue actuellement. Nous laisserons de côté le problème de l'appétit très important à cette période de la vie de l'animal et dont le contrôle permettrait d'utiliser plus rationnellement les nourrisseurs automatiques.

\title{
COMPOSITION DU PORC AU COURS DE LA CROISSANCE
}

\author{
(tabl. I et 2)
}

A sa naissance le porcelet contient I I p. roo de protéines et I,4 p. roo de lipides. Après la naissance, la synthèse des lipides est rapidement importante et dépasse légèrement celle des protéines (en poids). Vers 4 à $5 \mathrm{~kg}$ ( 2 semaines), la teneur du porcelet en protéines atteint $\mathrm{r} 5 \mathrm{p}$. 100 et sa teneur en lipides i 6 p. Ioo (MANNERs et MCCREA, I963; BERGE et INDREBø, I954; EsLEY, I963). La crise des 3 semaines se traduit par une diminution de la consommation d'aliments ce qui entraîne un certain amaigrissement : les tissus synthétisés sont plus pauvres en lipides ( 13 p. Ioo au lieu de 20 p. roo). La composition du croît reste ensuite constante jusqu'à $35^{-} 40 \mathrm{~kg}:$ I 5 à I $7 \mathrm{p}$. Ioo de protéines, 15 à 20 p. Ioo de lipides. A la naissance, les protéines du tissu musculaire ne correspondent qu'à Io p. roo de celui-ci; elles augmentent ensuite progressivement, atteignant I6 p. I00 à 3 semaines $(5,7 \mathrm{~kg}$ ) et I9-20 p. Ioo à 8 semaines (20 kg), (DURANd et al., I967 b).

TABLEAU I

Composition des porcelets au cours de la croissance, comparaison avec les éléments ingérés

\begin{tabular}{|c|c|c|c|c|c|c|c|c|c|}
\hline Réf. & $\begin{array}{l}\text { Age } \\
\text { (semai- } \\
\text { nes) }\end{array}$ & $\begin{array}{l}\text { Poids } \\
(\mathrm{kg})\end{array}$ & $\begin{array}{c}\mathrm{ED} \\
(\mathrm{kcal})\end{array}$ & $\begin{array}{c}\text { Croissance } \\
(g / j)\end{array}$ & $\begin{array}{l}\text { Protéines } \\
\text { fixées } \\
(g / j)\end{array}$ & $\begin{array}{l}\text { Protéines } \\
\text { fixées } \\
(\mathrm{kcal} / \mathrm{j})\end{array}$ & $\begin{array}{l}\text { Lipides } \\
\text { fixés } \\
(\mathrm{kcal} / \mathrm{j})\end{array}$ & $\left|\begin{array}{c}\text { Protéines } \\
\text { (kcal\% } \% \text { kcal } \\
\text { déposées) }\end{array}\right|$ & $\begin{array}{l}\text { Protéines } \\
\text { fixées } \\
\text { (kcal } \\
\% \text { ED) }\end{array}$ \\
\hline 2 & 2 & 3,4 & 1115 & 222 & 32 & 182 & 440 & 29,0 & 16,4 \\
\hline 1 & 2 & 3,7 & & 225 & 32,2 & 183,5 & 447 & 29,0 & \\
\hline 1 & 3 & 4,75 & & 166 & 22,6 & 129 & 209 & 38,1 & \\
\hline 2 & 3 & 5,0 & 1255 & 240 & 36,4 & 208 & 500 & 29,4 & 16,6 \\
\hline 1 & 5 & 6,80 & & 181 & 26,9 & 153 & 336 & 31,2 & \\
\hline 2 & 4 & 6,75 & 1430 & 258 & 38,8 & 222 & 550 & 28,7 & 15,5 \\
\hline 2 & 5 & 8,7 & 1660 & 281 & 42,0 & 240 & 600 & 28,6 & 14,5 \\
\hline 1 & 7 & 10,4 & & 360 & 50,6 & 288 & 552 & 34,2 & \\
\hline 2 & 6 & 10,8 & 1930 & 326 & 49,0 & 280 & 700 & 28,6 & 14,5 \\
\hline 2 & 7 & 13,4 & 2315 & 408 & 61,2 & 350 & 800 & 30,4 & 15,1 \\
\hline 1 & 8 & 14,4 & & 482 & 67,5 & 385 & 723 & 34,7 & \\
\hline 2 & 8 & 16,1 & 2750 & 385 & 61,2 & 350 & 800 & 30,4 & 13,0 \\
\hline 1 & 9 & 16,8 & & 353 & 55,5 & 316 & 515 & 38,0 & \\
\hline 1 & 10 & 18,8 & & 286 & 46,9 & 267 & 412 & 39,3 & \\
\hline 2 & 8 & 20,4 & 4000 & 521 & 78 & 440 & 1100 & 28,5 & 11 \\
\hline
\end{tabular}

1. BERGE, INDREBø, (1954).

2. LuCAS, (1962). 
TABLEAU 2

Composition du porc au cours de la croissance, comparaison avec les éléments ingérés

\begin{tabular}{|c|c|c|c|c|c|c|c|}
\hline Exp. & $\begin{array}{c}\text { Poids } \\
\text { (kg) }\end{array}$ & $\begin{array}{l}\text { Énergie } \\
\text { métabol. }\end{array}$ & $\begin{array}{c}\text { Protéines } \\
\text { fixées } \\
(\mathrm{g} / \mathrm{j})\end{array}$ & $\begin{array}{l}\text { Protéines } \\
\text { fixées } \\
(\mathrm{kcal} / \mathrm{j})\end{array}$ & $\begin{array}{l}\text { Lipides } \\
\text { fixés } \\
(\mathrm{kcal} / \mathrm{j})\end{array}$ & $\begin{array}{l}\text { Protéines } \\
\text { \% kcal } \\
\text { déposées }\end{array}$ & $\begin{array}{l}\text { Protéines } \\
\text { fixées (kcal } \\
\% \text { E M) }\end{array}$ \\
\hline 1 & 24 & 2663 & (72) & $(410)$ & $(-17)$ & $(100)$ & 15,4 \\
\hline 2 & $20-30$ & - & 115 & 655 & - & - & - \\
\hline 1 & 29 & 3377 & 89 & 508 & 326 & 61 & 15,0 \\
\hline 2 & $30-40$ & 3400 & 109 & 536 & 1128 & 32,2 & 15,8 \\
\hline 1 & 36 & 4017 & 101 & 577 & 738 & 44 & 14,4 \\
\hline 1 & 44 & 14878 & 107 & 611 & 1105 & 36 & 12,5 \\
\hline 2 & $40-50$ & 4500 & 103 & 599 & 1780 & 25,2 & 13,3 \\
\hline 1 & 52 & 5875 & 120 & 685 & 1825 & 27 & 11,6 \\
\hline 2 & $50-60$ & 5600 & 110 & 622 & 2481 & 20,0 & 11,1 \\
\hline 1 & 61 & 6803 & 125 & 713 & 2418 & 23 & 10,5 \\
\hline 2 & $60-70$ & 6600 & 117 & 641 & 3127 & 17,0 & 9,7 \\
\hline 1 & 72 & 7736 & 127 & 725 & 2951 & 20 & 9,4 \\
\hline 2 & $70 \cdot 80$ & 7700 & 112 & 635 & 3780 & 14,4 & 8,2 \\
\hline 1 & 83 & 8662 & 126 & 722 & 3536 & 17 & 8,3 \\
\hline 2 & $80-90$ & 8100 & 111 & 611 & 3631 & 14,4 & 7,5 \\
\hline 2 & $90-100$ & 8400 & 105 & 580 & 3604 & 13,9 & 6,9 \\
\hline 2 & $100-110$ & 8900 & 104 & $53 \%$ & 3861 & 12,2 & 6,0 \\
\hline 2 & $110-120$ & 9250 & 105 & 568 & 3871 & 12,8 & 6,1 \\
\hline
\end{tabular}

Exp. 1. ThORBEK (1968) gain moyen $636 \mathrm{~g} / \mathrm{j}$ pour porcs de 24 à $83 \mathrm{~kg}$.

Exp. 2. Oslage, Fliegel (1964) gains moyen $735 \mathrm{~g} / \mathrm{j}$ pour porcs de 25 à $110 \mathrm{~kg}$.

Le sevrage classique vers $16-20 \mathrm{~kg}$ provoque temporairement une synthèse des lipides plus faible, cependant que la synthèse des protéines continue régulièrement d'augmenter jusqu'à $30-35 \mathrm{~kg}$, où elle atteint 100 à I $25 \mathrm{~g}$ par jour chez le Large White, le porc Danois, le Landrace allemand et le Piétrain, (Thorber, i968; Oslage et Fliegel, I964; Farries et al., I968). La synthèse des protéines reste constante de 30 à $80 \mathrm{~kg}$ tandis que la synthèse des lipides augmente régulièrement après $35-40 \mathrm{~kg}$, d'autant plus que le niveau d'alimentation est plus élevé. La matière fraîche du croît contient $37 \mathrm{p}$. Ioo de lipides à $35 \mathrm{~kg}, 47 \mathrm{p}$. Ioo à $70-80 \mathrm{~kg}$ et $50 \mathrm{p}$. Ioo à 9o-Ioo $\mathrm{kg}$ (Thorbek, 1968; Oslage et Fliegel, 1964).

L'augmentation du niveau d'alimentation du porcelet (vers ro $\mathrm{kg}$ ) conduit à plus accélérer la lipogenèse (20-2I p. Ioo contre I5-I6 p. IOo) que la protéinogenèse et accroit la vitesse de croissance si l'apport azoté est suffisant (BOAZ et ElSzEY, 1962). Chez le porc plus âgé, (après $30 \mathrm{~kg}$ ) recevant un apport azoté suffisant, la quantité de protéines fixées ( 100 à $\mathbf{I} 25 \mathrm{~g} / \mathrm{j}$ ) est indépendante de la vitesse de croisance qui dépend du niveau d'alimentation, et la lipogenèse est proportionnelle à ce dernier. Lorsque l'apport des autres éléments de la ration : acides aminés indispensables, vitamines et minéraux est suffisant, la restriction énergétique provoque une croissance ralentie et un enrichissement des tissus en protéines (HeNk et LAUBE, 1967). La quantité de protéines fixées par jour reste à peu près constante si la carence énergétique n'est pas trop poussée (75-80 p. Ioo des normes). La rétention azotée quotidienne du porc de 30 à $90 \mathrm{~kg}$ semble dépendre essentiellement des facteurs génétiques (HENK et LAUBE, 1967). 


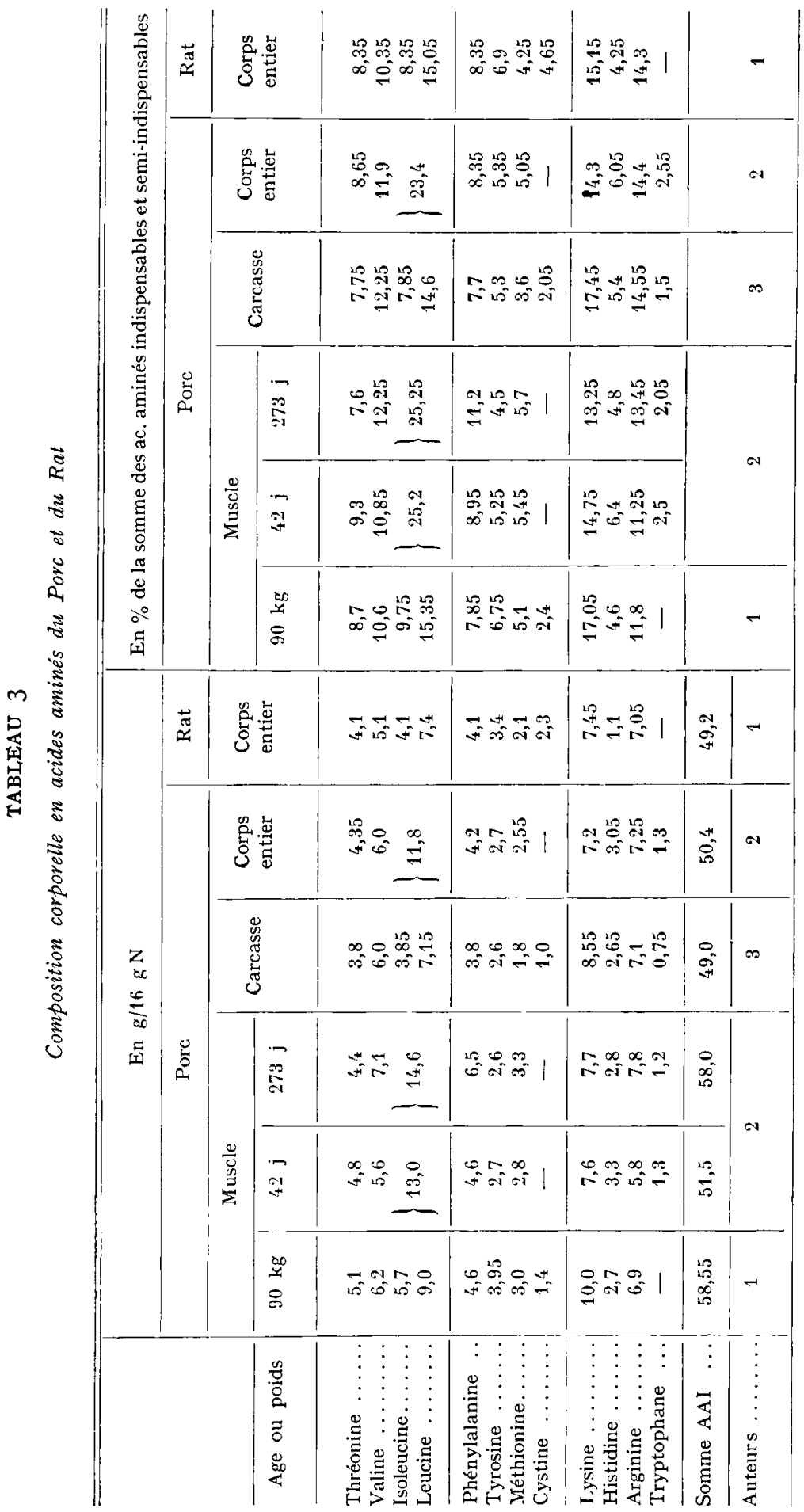


En outre, une croissance rapide obtenue grâce à un niveau d'alimentation élevé chez le porcelet (vers $15 \mathrm{~kg}$ ) n'a pas de conséquences économiques intéressantes sur la croissance ultérieure, l'indice de consommation et les qualités de la carcasse (à $90 \mathrm{~kg}$ ) (ElsLey, 1963).

L'étude plus fine de la croissance de divers tissus du porc analysant le rôle respectif de l'hyperplasie et de l'hypertrophie au cours de celle-ci, a été effectuée par STRunz et LENKEIT (rg63), par DuRAND et al. (I967 a). L'hyperplasie est le principal facteur de développement du tissu musculaire jusqu'à $70 \mathrm{~kg}$ (puberté?), puis 1'hypertrophie devient prépondérante. Au cours de la croissance, la carence énergétique ralentit plus la multiplication nucléaire que la synthèse protéique (DURAND et PENot, I970), mais diminue cependant le rapport $\frac{\text { RNA }}{\text { DNA }}$.

La restriction azotée provoque un effondrement du rapport $\frac{\mathrm{DNA}}{\mathrm{RNA}}$, mais l'augmentation du DNA se poursuit à une vitesse variable suivant les tissus : la multiplication est peu freinée dans le cour cependant que dans les autres tissus musculaires la diminution de synthèse du DNA est du même ordre de grandeur que celle de la synthèse protéique (STrunz et LENkEIT, I963).

La composition en acides aminés indispensables de l'ensemble des protéines corporelles du Porc paraît voisine de celle du Rat (GRuhN, I965; Williams et al., 1964) (tabl. 3) ; la composition du muscle de porc est très voisine de celle des muscles de veau et de bouf (PION et FauconnEaU, I968).

\section{CONSÉQUENCES SUR LES BESOINS AZOTÉS}

Le rapport $\frac{\text { énergie métabolisable }}{\text { protéines fixées }}$ est constant chez le porc de 5 à $30-35 \mathrm{~kg}$ (I 5-I $6 \mathrm{p}$. Ioo) puis diminue ensuite régulièrement jusqu'à $120 \mathrm{~kg}$ (tabl. I et 2) (OSLAGE et FliegEL, I964; Hornicke, I96I). Cette évolution caractéristique de la protéinogenèse chez le porc a diverses conséquences nutritionnelles : de 5 à $30 \mathrm{~kg}$, la concentration des acides aminés indispensables pour la croissance doit rester sensiblement constante dans l'énergie de la ration exprimée en énergie digestible (ED) ou en énergie métabolisable $(\mathrm{EM}=\mathrm{ED} \times(0,93 \pm 0,02)$ par $\mathrm{kg}$; cet énergie métabolisable est très élevée (4 $500 \mathrm{kcal} / \mathrm{kg}$ de MS), car le porcelet consomme des rations riches en lipides.

Entre 30 et $90 \mathrm{~kg}$, le rapport $\frac{\text { énergie métabolisable }}{\text { protéines fixées }}$ diminue de I 5 à 8 p. Ioo : les acides aminés indispensables apportés par la ration, et nécessaires chaque jour à la protéinogenèse qui est constante, sont de plus dilués dans l'energie nécessaire à la lipogénèse et à l'entretien. Une ration comportant $200 \mathrm{~g}$ de protéines bien équilibrées en acides aminés indispensables permet la fixation dans l'organisme de $60 \mathrm{p}$. Ioo de l'azote digéré (FARries et al., i968; ТноrBeк, I968). Ces $200 \mathrm{~g}$ doivent être contenus respectivement dans $\mathrm{I}, 2$ et $3 \mathrm{~kg}$ de ration contenant 3 ooo kcal d'énergie digestible par $\mathrm{kg}$ de MS pour des porcs de 25,45 et $80 \mathrm{~kg}$ (A. R. C. I967). Il faut ajouter au besoin de croissance une certaine quantité de protéines nécessaires à l'entretien ( 3 p. roo de la ration). L'alimentation séparée en protéines d'une part, et en glucides-lipides d'autre part, (apportant l'énergie), serait intéressante pendant cette phase de croissance-engraissement (HENRY, r968), car l'alimentation ad libitum entraîne un gaspillage d'énergie très important chez les porcs dont le poids dépasse $35 \mathrm{~kg}$. En effet, l'animal a du mal à ajuster simultanément à ses besoins les apports de calories et d'acides aminés indispensables. La diminution des ingesta, liée à l'augmentation de la concentration énergétique de la ration que RÉRAT et LougNon (1966) ont trouvée n'est pas confirmée par CLAwson ( 1967 ) dans le cas où les protéines de la ration sont bien équilibrées.

En résumé, si de 5 à $30 \mathrm{~kg}$, les acides aminés indispensables doivent être apportés proportionnellement à l'énergie métabolisable, en revanche, l'apport d'acides aminés indispensables doit être relativement constant, après $33 \mathrm{~kg}$, et n'est accru que par l'augmentation du besoin d'entretien. 


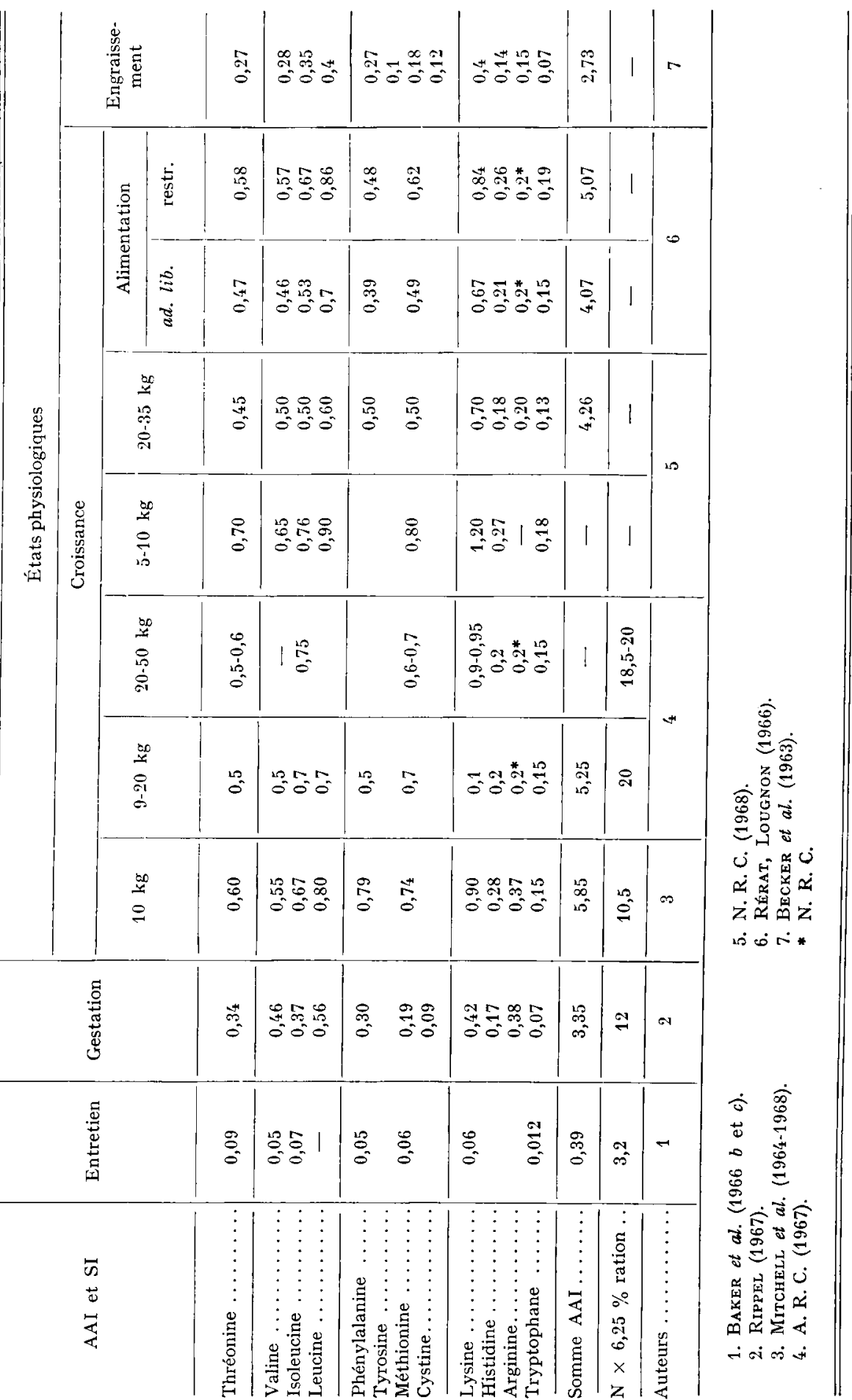




\section{BESOINS EN ACIDES AMINÉS INDISPENSABLES}

Les besoins azotés ont fait l'objet de nombreuses mises au point récentes (RúRAT et LougNon, I 66 ; A. R. C., I967; Номв et Matre, I967; N. R.C., I968). Le besoin azoté du porc et des autres espèces, correspond au besoin d'une dizaine de L-acides aminés indispensables qui doivent être apportés dans les rations en proportion équilibrée et en rapport avec l'énergie métabolisable de celles-ci. Les études ont généralement été réalisées avec des rations mixtes dont on ne connait ni la disponibilité des acides aminés, ni l'efficacité de la supplémentation ; ces rations ont rarement fait appel, sauf dans le cas de la méthionine, à l'utilisation d'acides aminés inđispensables libres, contrairement à ce qui a été réalisé dans le cas du Rat et de la Volaille. Toutefois Mitchell et al. (I964-I969) ont effectué quelques déterminations des besoins en acides aminés indispensables du porcelet $(8-15 \mathrm{~kg})$; ils ont étudié particulièrement l'isoleucine, la thréonine, la valine, le tryptophane et les acides aminés soufrés.

\section{TABIEAU 5}

Besoins en acides aminés indispensables et semi-indispensables du porc (en p. Ioo de leur somme)

\begin{tabular}{|c|c|c|c|c|c|c|c|c|c|}
\hline & \multirow{3}{*}{ Entretien } & \multirow{3}{*}{ Gestation } & \multicolumn{5}{|c|}{ Croissance } & \multirow{3}{*}{$\begin{array}{l}\text { Engrais- } \\
\text { sement }\end{array}$} & \multirow{3}{*}{$\begin{array}{l}\text { Besoins du } \\
\text { Rat en } \\
\text { croissance }\end{array}$} \\
\hline & & & \multirow{2}{*}{$\begin{array}{l}10 \\
\mathrm{~kg}\end{array}$} & \multirow{2}{*}{$\begin{array}{c}9-20 \\
\mathrm{~kg}\end{array}$} & \multirow{2}{*}{$\begin{array}{c}20-35 \\
\mathrm{~kg}\end{array}$} & \multicolumn{2}{|c|}{ Alimentation } & & \\
\hline & & & & & & Ad lib. & Restr. & & \\
\hline Thréonine & 22,5 & 10,1 & 10,25 & 9,5 & 10,55 & 11,0 & 11,0 & 9,9 & 9,15 \\
\hline Valine ...... & 12,5 & 13,7 & 9,4 & 9,5 & 11,75 & 10,75 & 10,8 & 10,25 & 10,1 \\
\hline Isoleucine . . . & 17,5 & 11,0 & 11,5 & 13,3 & 11,75 & 12,4 & 12,7 & 12,3 & 10,1 \\
\hline Leucine . . . . . & - & 16,7 & 13,7 & 13,3 & 14,1 & 18,4 & 16,3 & 14,65 & 13,4 \\
\hline Phénylalanine & 12,5 & 8,9 & 13,5 & 9,5 & 11,75 & 9,1 & 9,1 & 9,9 & 13,95 \\
\hline Tyrosine .... & - & $一$ & - & - & - & - & - & 3,65 & - \\
\hline Méthionine ... & 15,0 & 5,7 & 12,65 & 13,3 & 11,75 & 11,45 & 11,75 & 6,6 & 11,0 \\
\hline Cystine ...... & - & 2,7 & - & - & - & - & - & 4,4 & - \\
\hline Lysine . . . . . & $15^{\prime} 0$ & 12,5 & 15,4 & 20,9 & 16,4 & 15,7 & 15,9 & 14,65 & 17,4 \\
\hline Histidine .... & - & 5,1 & 4,8 & 3,8 & 4,25 & 4,9 & 4,9 & 5,1 & 4,6 \\
\hline Arginine $\ldots .$. & 一 & 11,3 & 6,3 & 3,8 & 4,7 & $4,7^{*}$ & $3,8^{*}$ & 5,5 & 7,5 \\
\hline Tryptophane & 3,0 & 2,1 & 2,55 & 2,85 & 3,05 & 3,5 & 3,6 & 2,55 & 2,75 \\
\hline Auteurs & 1 & 2 & 3 & 4 & 5 & 6 & & 7 & 8 \\
\hline
\end{tabular}

1. BAKER et al. (1966b et $c)$.

2. RIPPEL (1967).

3. Mitchell et al. (1964-1968).

4. A. R. C. (1967).

5. N. R. C. (1968).

6. Rerat, Lougnon (1966).

7. BECKER et al. (1963).

8. Ranhotra, Johnson (1965.)

* N. R. C. 
Les besoins de chaque acide aminé indispensable exprimés en p. roo de leur somme (PIon, de Belsunce et Fauconneau, r963) (tabl. 5) peuvent être comparés aux besoins préconisés par les différents auteurs dans les divers états physiologiques des animaux. Ce mode d'expression permet, en outre, de faire relativement abstraction du rapport : $\frac{\text { acides aminés indispensables }}{\text { énergie métabolisable }}$ d'analyser avec précision l'aptitude des aliments à couvrir les besoins du point de vue de l'équilibre des acides aminés indispensables. La comparaison des recommandations proposées par les divers auteurs fait apparaître des divergences plus faibles qu'autrefois (FAUConneau, 1966). Cette évolution est nette dans le cas de la leucine et de l'isoleucine. Les besoins en ces acides aminés paraissent plus importants chez le porc de 20 à $50 \mathrm{~kg}$ que chez le porcelet de $10 \mathrm{~kg}$, et que chez les autres espèces : $16 \mathrm{p}$. Ioo contre $\mathrm{r} 3,4 \mathrm{p}$. roo pour la leucine, $\mathrm{I} 4 \mathrm{p}$. Ioo contre $\mathrm{I} 2 \mathrm{p}$. Ioo pour l'isoleucine (Rérat et Lougnon, 1966). Ce fait était vraisemblablement lié à l'utilisation de rations à base de maïs pour la détermination des besoins des porcs de 20 à $50 \mathrm{~kg}$. Or, les protéines du maïs ont une teneur en leucine très élevée, ce qui peut entraîner à la fois une surestimation du besoin en leucine, et une augmentation du besoin en isoleucine (Spolter et Harper, 196r). Les résultats récents d'expériences effectuées avec des rations mixtes ne font plus apparaitre cette originalité du Porc; les besoins en acides aminés indispensables pour la croissance de cette espèce (exprimés en p. ıoo de leur somme) seraient voisins de ceux du Rat.

\section{INFLUUENCE DE L'ÂGE}

Les besoins en la plupart des acides aminés indispensables diminuent régulièrement avec l'âge; seul le besoin en méthionine ne diminue que lentement chez les porcs de plus de $60 \mathrm{~kg}$, (Navratil et Simeneck, I963; Wiesembller et Poppe, i968).

Le besoin en lysine du porcelet $(5-15 \mathrm{~kg})$, déterminé par ANderson et Bowland (1967) paraît plus élevé ( 1,18 p. 100 de la matière sèche de la ration) que celui des animaux plus âgés. En fait, la ration utilisée contenait 22 p. too de protéines et 4 ooo kcal d'énergie digestible par kg de matière sèche, et le besoin ainsi déterminé correspond à $0,90 \mathrm{p}$. roo d'une ration à 3 o5o kcal d'ED/kg de MS ; FENDER (I968) a d'ailleurs trouvé pour des porcs de 20 à $40 \mathrm{~kg}$ un besoin en lysine de $\mathrm{I}, \mathrm{I} 8 \mathrm{p}$. Ioo pour une ration contenant 4 ooo $\mathrm{kcal}$ d'énergie digestible par $\mathrm{kg}$. Le besoin en lysine, rapportée à la matière sèche de la ration, des très jeunes porcelets n'est donc plus élevé que dans le cas où ils reçoivent une ration très riche en lipides.

La proportionnalité entre les acides aminés indispensables et l'énergie de la ration paraît s'imposer pour l'alimentation azotée des porcs jusqu'à $4^{\circ} \mathrm{kg}$. En revanche, chez les porcs plus âgés $(40-80 \mathrm{~kg})$, le besoin en acides aminés indispensables n'est plus proportionnel à la concentration énergétique de la ration ; c'est ainsi que RÉRAT et HENRY (I969) trouvent un besoin de $0,52 \mathrm{p}$. roo de méthionine pour des femelles recevant un régime contenant $345^{\circ} \mathrm{kcal} \mathrm{d}$ 'ED $/ \mathrm{kg}$ au lieu de $0,5 \mathrm{p}$. roo trouvés par la plupart des auteurs pour des régimes comportant 3 ooo kcal d'ED/kg.

Les résultats de WIESEMÜLLeR et POPPE (1968) obtenus avec des rations mixtes et variées montrent que le besoin quotidien en lysine augmente rapidement pour des porcs de 20 à $40 \mathrm{~kg}$ (9-I $4 \mathrm{~g} / \mathrm{j})$, proportionnellement aux protéines fixées $(70-\mathrm{T} \mathrm{To} \mathrm{g} / \mathrm{j})$.Le besoin augmente plus lentement chez les animaux plus âgés, ce qui correspond partiellement à l'augmentation du besoin d'entretien en fonction du poids métabolique : 0,7 à $0,8 \mathrm{~g} / \mathrm{j}$ de lysine supplémentaire sont nécessaires par ıo $\mathrm{kg}$ de poids vif ; c'est-à-dire à 0.2 p. Ioo de lysine dans la ration. Ce résultat correspond à trois fois le besoin d'entretien trouvé chez des truies de $150 \mathrm{~kg}$. En tenant compte des quantités ingérées, le besoin en lysine exprimé en p. Ioo de la ration diminue d'abord lentement jusqu'à $40 \mathrm{~kg}$, puis plus rapidement ensuite (tabl. 6). 


\section{TABLEAU 6}

Besoins en lysine et en méthionine du porc

(en p. Ioo de leur somme)

\begin{tabular}{|c|c|c|c|c|c|c|c|c|}
\hline MS ingérées $(\mathrm{kg})$ & 1 & 1,4 & 1,7 & 2,0 & $2,{ }^{\prime}$ & 2,7 & 3,0 & 3,1 \\
\hline Poids $(\mathrm{kg})$ & 20 & 30 & 40 & 50 & 60 & 70 & 80 & 90 \\
\hline Lysine & & & & & & & & \\
\hline $\mathrm{g} / \mathbf{j} \ldots \ldots$ & 9,0 & 12,0 & 14,0 & 15,0 & 15,8 & 16,4 & 16,8 & 17,3 \\
\hline p. 100 MS ingérées ... & 0,90 & 0,86 & 0,83 & 0,75 & 0,66 & 0,61 & 0,56 & 0,56 \\
\hline Méthionine & & & & & & & & \\
\hline$\ldots \ldots$ & 5,2 & 7,1 & 8,5 & 10,0 & 11,3 & 11,8 & 12,0 & 12,0 \\
\hline p. 100 MS ingérées ... & 0,52 & 0,51 & 0,50 & 0,50 & 0,47 & 0,44 & 0,40 & 0,39 \\
\hline
\end{tabular}

Wiesemüller, Poppe, (1968.)

Le besoin journalier en méthionine augmente plus rapidement avec l'âge et le poids que le besoin en lysine : entre 20 et $50 \mathrm{~kg}$, le besoin en méthionine est doublé alors que celui en lysine n'est augmenté que de $65 \mathrm{p}$. Ioo. La divergence des besoins en méthionine et lysine au cours de la croissance est liée, d'une part à la faible teneur relative des tissus synthétisés en méthionine et cystine, 3 à $3,5 \mathrm{~g} / \mathrm{I} 6 \mathrm{~g}$ d' $\mathrm{N}$ au lieu de 7,5 pour la lysine, et d'autre part aux besoins importants de méthionine pour l'entretien (BAKER et al., 1966). La méthionine assure en effet diverses fonctions de détoxication au niveau de l'organisme et les acides aminés soufrés se trouvent en concentration relativement importante dans les phanères. Rapporté à la ration, le besoin en méthionine du jeune porc de $20 \mathrm{~kg}$ ne correspond qu'à $60 \mathrm{p}$. Ioo du besoin en lysine alors qu'il est de $72 \mathrm{p}$. Ioo du même besoin chez le porc de $80 \mathrm{~kg}$.

Les normes préconisées par l'A.R.C. (tabl. 4 et 5 ) pour la lysinesont particulièrement élevées pour le porc de 40 à $50 \mathrm{~kg}(0,9$ à $0,95 \mathrm{p}$. Ioo de lysine) et pour le jeune porcelet de 2 à $9 \mathrm{~kg}(2,2$ à I,5 p. Ioo de lysine). L'utilisation de telles normes avec des rations bien équilibrées en acides aminés indispensables chez le porc de 50 à $90 \mathrm{~kg}$ conduit à des rendements faibles de l'azote digéré: 3o à 50 p. Ioo (Oslage et Flieger, I964; Farries et al., I968; THORbeK, I968) alors que le jeune porcelet de 20 à $30 \mathrm{~kg}$ retient 50 à $60 \mathrm{p}$. roo de l'azote absorbé.

\section{ACIDES AMINÉS LIBRES DU SANG ET ÉTAT DE NUTRITION AZOTÉE}

Les acides aminés libres du sang, et, en particulier du plasma constituent la principale forme de transport vers les tissus des produits de la digestion et de l'absorption des matières azotées alimentaires. Leurs concentrations sont à chaque instant le résultat de l'équilibre entre les apports d'acides aminés alimentaires ou provenant du catabolisme des protéines, et la synthèse de protéines nouvelles.

Lorsqu'un acide aminé est fourni à l'animal en quantité supérieure à son besoin, sa teneur dans le sang augmente, et n'est limitée que par l'aptitude des organes à le cataboliser. Dans le cas contraire, les tissus qui ont à leur disposition les autres nutriments, et en particulier les autres acides aminés qui leur sont nécessaires pour synthétiser des protéines, vont prélever l'acide aminé limitant dès son arrivée dans le sang, et sa teneur y sera diminuée. 
Des relations ont ainsi pu être établies chez le Rat et le Poulet entre les concentrations en acides aminés dans le plasma ou dans le sang total, et le degré de satisfaction du besoin, au moins pour un certain nombre d'acides aminés. Des études similaires ont été entreprises chez le Porc par un certain nombre d'équipes.

Une des difficultés de ces études est le choix du moment auquel les échantillons de sang doivent être prélevés, en fonction du rythme alimentaire de l'animal. L'influence de l'aliment risque d'être prépondérante pendant les premières heures qui suivent le repas, et les concentrations alors mesurées risquent de dépendre plus des apports que de l'utilisation. Les concentrations mesurées dans des prélèvements effectués après un jeûne trop prolongé risquent d'être modifiées par le catabolisme tissulaire. Il est bien difficile de choisir un optimum et plusieurs techniques ont été utilisées :

- les animaux sont nourris ad libitum, et les prélèvements sont effectués sans aucun jeûne préalable (Puchal et al., I962) ;

- les animaux sont soumis à un jeûne de durée variable, à la suite duquel des prises desang sont effectuées, (Chance, I962, Richardson et al., 1965) ;

- les animaux sont soumis à des repas, et les prélèvements sont effectués à des temps variables après l'ingestion de ce dernier. (Long et al., r965; KRYSCraK et al., I966; ComBs et al., 1967; Сооке et al., I966). Les repas sont plus ou moins espacés selon les auteurs, et souvent précédés d'un jeûne de $\mathrm{I} 2$ à $\mathbf{I} 8$ heures.

Plusieurs auteurs, et en particulier CHANCE, ont utilisé concurremment deux de ces techniques.

TABLEAU 7

Composition moyenne en acides amines libres du sang et du plasma du porc $(\mu \mathrm{g} / \mathrm{ml})$

\begin{tabular}{|c|c|c|c|c|c|c|}
\hline \multirow[b]{2}{*}{ Régime } & \multicolumn{3}{|c|}{ Sang total } & \multicolumn{3}{|c|}{ Plasma } \\
\hline & $\begin{array}{c}\text { Farine } \\
\text { de poisson }\end{array}$ & $\begin{array}{l}\text { Blé lysine } \\
\text { tryptophane }\end{array}$ & $\begin{array}{l}\text { Tournesol } \\
\text { lysine } \\
\text { tryptophane }\end{array}$ & $\begin{array}{c}\text { Maïs soja } \\
\text { lait }\end{array}$ & Maïs soja & $\begin{array}{l}\text { Mais farine } \\
\text { de poisson }\end{array}$ \\
\hline Acide aspartique ... & 5 & 5 & 5 & 2 & 3 & tr. \\
\hline Thréonine ....... & 9 & 8 & 8 & 18 & 21 & 31 \\
\hline Acide glutamique .. & 20 & 17 & ND & 21 & 22 & 33 \\
\hline Proline........... . & ND & 29 & 19 & 47 & 31 & 33 \\
\hline Citrulline $\ldots \ldots \ldots$ & 7 & 12 & 12 & & 15 & 16 \\
\hline Glycine $\ldots \ldots \ldots$. & 41 & 69 & 68 & 58 & 54 & 123 \\
\hline Alanine....$\ldots$. & $2 \prime$ & 40 & 31 & 67 & 42 & 54 \\
\hline Valine $\ldots \ldots \ldots \ldots$ & 19 & 22 & 31 & 30 & 28 & 35 \\
\hline Cystine $\ldots \ldots \ldots \ldots$ & ND & ND & 7 & 12 & 5 & 9 \\
\hline Méthionine...$\ldots$. & ND & ND & 7 & 6 & tr. & 8 \\
\hline Isoleucine $\ldots . . . \ldots$. & ) & 12 & 13 & 18 & 17 & 18 \\
\hline Leucine . . . . . . . & 37 & 16 & 15 & 30 & 21 & 23 \\
\hline Phénylalanine & & 9 & 7 & 16 & 10 & 8 \\
\hline Tyrosine ........ & 6 & 10 & 7 & 28 & 17 & 11 \\
\hline Ornithine $\ldots \ldots \ldots$ & i & 14 & 20 & - & 50 & 54 \\
\hline Lysine . . . . . . . . & 15 & 21 & 30 & 26 & 23 & 31 \\
\hline Histidine $\ldots \ldots \ldots$ & ND & 11 & 8 & 15 & 14 & 18 \\
\hline \multirow{3}{*}{$\begin{array}{l}\text { Arginine } \ldots \ldots \ldots \ldots \\
\text { Méthode } \ldots \ldots \ldots\end{array}$} & ND & 19 & ND & 26 & 21 & 33 \\
\hline & $\begin{array}{c}\text { chromato. } \\
\text { papier }\end{array}$ & colonne & colonne & colonne & colonne & colonne \\
\hline & \multicolumn{3}{|c|}{ Pion, Rérat : 1964, 1967, 1969} & $\begin{array}{c}\text { Chance } \\
1962\end{array}$ & \multicolumn{2}{|c|}{ Puchal et al., 1962} \\
\hline
\end{tabular}


Les résultats obtenus actuellement sont encore partiels, et méritent d'être complétés par de nouvelles expérimentations; il est toutefois possible d'en tirer un certain nombre de conclusions : les valeurs moyennes obtenues par différents auteurs (tabl. 7) sont assez comparables au moins en ce qui concerne les acides aminés indispensables. Les différents régimes utilisés doivent satisfaire les besoins des animaux, mais peuvent contenir certains acides aminés en quantités supérieures aux besoins.

Il ne semble pas y avoir de différences entres les concentrations en acides aminés plasmatiques déterminées chez les mâles et chez les femelles, contrairement à ce qui est observé en ce qui concerne l'urée, (Chance, r962).

TABLEAU 8

Influence du jeûne sur la composition en acides aminés libres du plasma du porc

\begin{tabular}{|c|c|c|c|c|c|c|c|c|}
\hline & \multicolumn{8}{|c|}{ Temps de jeâne en heures } \\
\hline & 0 & 6 & 12 & 18 & 24 & 0 & 12 & 24 \\
\hline Thréonine........... & 33 & 21 & 15 & 18 & 22 & 22 & 12 & 16 \\
\hline Sérine ........... & 27 & 18 & 15 & 17 & 17 & 19 & 13 & 17 \\
\hline Glutamine ........ & 70 & 48 & 51 & 44 & 48 & & & \\
\hline Ac. glutamique ...... & 32 & 26 & 23 & 22 & 21 & 39 & 29 & 34 \\
\hline Proline $\ldots \ldots \ldots \ldots$ & 60 & 33 & 23 & 21 & 24 & 47 & 29 & 39 \\
\hline Citrulline . . . . . . & 18 & 15 & 13 & 13 & 14 & & & \\
\hline Glycine $\ldots \ldots \ldots \ldots$ & 71 & 67 & 68 & 50 & 53 & 16 & 34 & 50 \\
\hline Alanine $\ldots \ldots \ldots$ & 48 & 30 & 29 & 28 & 30 & 45 & 29 & 39 \\
\hline Valine $\ldots \ldots \ldots \ldots$ & 52 & 37 & 28 & 40 & 46 & 33 & 22 & 30 \\
\hline Isoleucine $\ldots \ldots \ldots$ & 27 & 19 & 13 & 20 & 22 & 20 & 14 & 17 \\
\hline Leucine. . . . . . . . . . & 43 & 30 & 21 & 31 & 32 & 33 & 22 & 26 \\
\hline Tyrosine $\ldots \ldots \ldots$ & 38 & 23 & 15 & 17 & 21 & 21 & 12 & 20 \\
\hline Phénylalanine ...... & 20 & 15 & 13 & 17 & 18 & 18 & 12 & 17 \\
\hline Ornithine ........ & 18 & 12 & 7 & 8 & 8 & 17 & 10 & 17 \\
\hline Lysine . . . . . . . . . & 31 & 18 & 16 & 27 & 31 & 25 & 17 & 27 \\
\hline Histidine ......... & 18 & 14 & 12 & 11 & 12 & 17 & 16 & 19 \\
\hline \multirow[t]{2}{*}{ Arginine $\ldots \ldots \ldots \ldots$} & 37 & 22 & 15 & 19 & 21 & 25 & 14 & 24 \\
\hline & \multicolumn{5}{|c|}{ d'après Chance, 1962} & \multicolumn{3}{|c|}{$\begin{array}{c}\text { d'après RichaRDson et al. } \\
1965\end{array}$} \\
\hline
\end{tabular}

Les concentrations de la plupart des acides aminés diminuent après 6 à $I 2$ heures de jeûne ; les teneurs en acides aminés indispensables augmentent à nouveau après I2, 24 ou 36 heures de jeûne, (Chance, 1962; Richardson et al., I965; Typpo et Meade, 1964) (tabl. 8), et continuent à augmenter au cours d'un jeûne prolongé (Cuperlovic et al., I968).

Les concentrations augmentent généralement après l'ingestion d'un repas, et présentent un ou deux pics, (COOKE et al., I966; LONG et al., 1965). Il y a très généralement une relation entre la composition des aliments protéiques ingérés, et les concentrations en acides aminés indispensables du plasma. En particulier, des supplémentations par des doses graduelles d'un acide aminé entraînent généralement une augmentation de la teneur du sang en cet acide aminé, (COOKE et al., I966; Mitchell et al., I968; Long et al., I965; Pick et Meade, I968). L'influence de l'alimentation se manifeste dès le premier repas (colostrum) (ČuperLovic, I967).

Les concentrations en acides aminés indispensables du plasma de porcs en croissance, recevant une ration de taux protéique constant, augmentent avec l'âge des animaux (tabl. 9) (CHAncE, 1962). Il semble que les apports alimentaires d'acides aminés indispensables deviennent progressivement excédentaires par rapport aux besoins, ce qui est en accord avec l'évolution de ces derniers au cours de la croissance. 


\section{TABLEAU 9}

Influence de l'âge sur la composition en acides aminés libres du plasma du porc ( $\mu \mathrm{g} / \mathrm{ml}$ de plasma)

\begin{tabular}{|c|c|c|c|c|c|c|c|c|}
\hline \multirow{2}{*}{$\begin{array}{c}\text { Taux protéique } \\
\text { de la ration p. } 100\end{array}$} & \multicolumn{6}{|c|}{$19,{ }_{4}^{\prime}$} & \multirow{2}{*}{$\frac{16,6}{15}$} & \multirow{2}{*}{$\begin{array}{r}13,5 \\
19\end{array}$} \\
\hline & 5 & 6 & 7 & 8 & 9 & 10 & & \\
\hline Thréonine.......... & 16 & 24 & 18 & 29 & 29 & 33 & 26 & 20 \\
\hline Sérine $\ldots \ldots \ldots \ldots$ & 21 & 35 & 35 & 37 & 32 & 27 & 24 & 24 \\
\hline Glutamine $\ldots \ldots \ldots$ & 64 & 82 & 78 & 100 & 91 & 70 & 70 & 70 \\
\hline Ac. glutamique ..... & 19 & 24 & 21 & 30 & 24 & 32 & 32 & 25 \\
\hline Proline $\ldots \ldots \ldots \ldots \ldots$ & 34 & 47 & 47 & 61 & 63 & 60 & 46 & 41 \\
\hline Citrulline $\ldots \ldots \ldots$ & 19 & 23 & 20 & 21 & 20 & 18 & 18 & 16 \\
\hline Glycine . . . . . . . & 47 & 60 & 58 & 76 & 72 & 71 & 83 & 78 \\
\hline Alanine $\ldots \ldots \ldots \ldots$ & 54 & 73 & 67 & 69 & 58 & 48 & 50 & 49 \\
\hline Valine $\ldots . . . \ldots \ldots$ & 28 & 33 & 30 & 40 & 46 & 52 & 40 & 35 \\
\hline Cystine...$\ldots \ldots$. & 13 & 14 & 12 & 18 & 13 & 22 & 19 & 17 \\
\hline Méthionine $\ldots .$. & 5,2 & 6,9 & 6,1 & 7,6 & 8,1 & 8,6 & 7,3 & 7,6 \\
\hline Isoleucine $\ldots \ldots \ldots$ & 18 & 23 & 18 & 22 & 24 & 27 & 19 & 16 \\
\hline Leucine. . . . . . . . & 26 & 32 & 30 & 38 & 40 & 43 & 33 & 31 \\
\hline Tyrosine $\ldots \ldots \ldots$ & 19 & 28 & 28 & 37 & 37 & 38 & 27 & 24 \\
\hline Phénylalanine ...... & 14 & 17 & 16 & 19 & 18 & 20 & 20 & 16 \\
\hline Ornithine $\ldots \ldots \ldots$ & 10 & 17 & 14 & 19 & 17 & 18 & 15 & 15 \\
\hline Lysine . . . . . . . . & 32 & 19 & $2 '$ & 29 & 33 & 31 & 29 & 22 \\
\hline Histidine ...... & 12 & 14 & 15 & 20 & 20 & 18 & 18 & 18 \\
\hline Arginine $\ldots \ldots \ldots$ & 21 & 24 & 26 & 35 & 35 & 37 & 38 & 31 \\
\hline Tryptophane ....... & 2,9 & 1,6 & 1,7 & 5,0 & 4,1 & $1,,^{\prime}$ & 4,3 & 9,6 \\
\hline
\end{tabular}

Chance, 1962.

Il n'est pas possible de considérer isolément les variations de concentration d'un acide aminé isolé. Il y a en effet, une interaction entre les concentrations des divers acides aminés; c'est ainsi que l'on constate très souvent une diminution de la teneur en thréonine du plasma lorsque la teneur en lysine de l'aliment et la teneur en lysine libre du sang augmentent. Ces phénomènes sont probablement dus à ce que la présence de lysine supplémentaire permet une synthèse protéique accrue, qui nécessite l'utilisation d'une proportion plus importante des apports des autres acides aminés alimentaires.

La détermination des concentrations plasmatiques en acides aminés peut constituer une méthode de détermination des besoins au moins en ce qui concerne certains acides aminés : isoleucine, lysine, histidine, leucine, (Mrtchell, 1965).

\section{ACIDES AMINÉS LIBRES DU SANG E'T DIGESTION}

L'étuce du sang périphérique ne permet pas de déterminer avec précision la cinétique des apports du tube digestif consécutifs à l'ingestion de protéines ou d'acides aminés. En effet, les produits de l'absorption risquent d'être modifiés en particulier par le foie. Aussi, est-il préférable, pour l'étude de l'utilisation digestive des protéines et des acides aminés, de mesurer les variations de concentration dans le sang de la veine porte. Nous avons ainsi étudié la digestion des protéines 
de la farine de hareng, de l'orge et de l'arachide, et comparé les courbes cinétiques obtenues pour chacune de ces protéines à celles qui étaient observées après l'ingestion de repas sans protéines (Pion et al., 1964).

Les observations faites dans ce dernier cas montrent que la part des apports endogènes est faible dans le cas des acides aminés indispensables. Les concentrations des divers acides aminés

TABLEAU IO

Variations de la teneur en quelques acides aminés libres du sang porte du porc au cours de la digestion du blé

(en p. Ioo de leur teneur dans le sang des animaux à jeun)

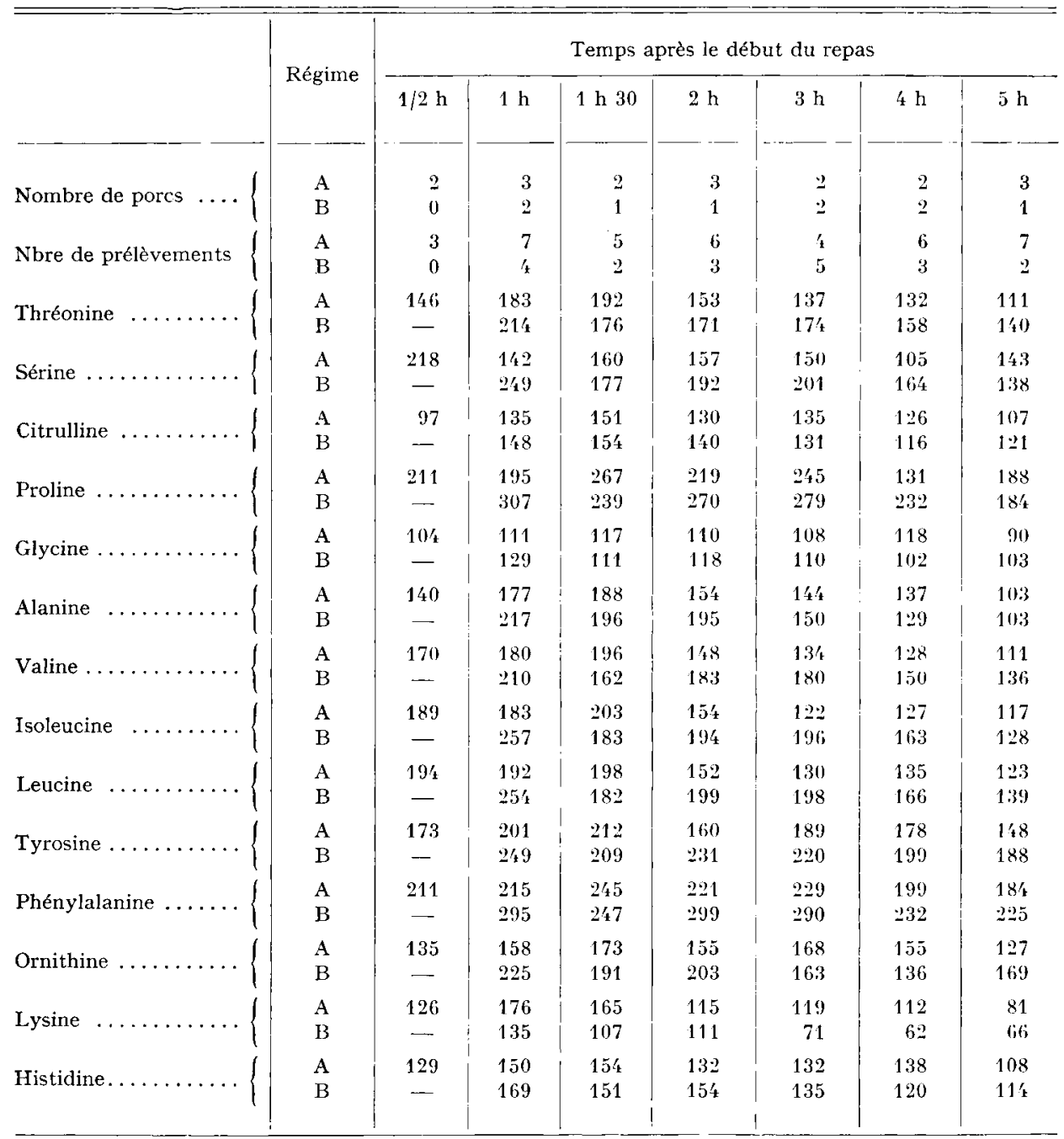

Régime A : ration blé-lysine-tryptophane.

Régime $\mathrm{B}$ : ration blé non supplémenté.

Pion, Rérat (1967). 
augmentent de façon parfois importante (200 p. 10o) deux à trois heures après les repas protéiques. Elles diminuent ensuite, pour retrouver le niveau du sang des animaux à jeun, 8 heures environ après le début du repas. Les courbes observées pour les acides aminés indispensables sont caractéristiques des protéines ingérées. Les augmentations de concentrations sont très élevées pour les acides aminés indispensables, dans le cas de la farine de poisson, et très faibles dans le cas de l'orge. Elles sont généralement importantes dans le cas de l'arachide, sauf en ce qui concerne les acides aminés limitants de cette protéine (lysine et thréonine en particulier).

\section{TABLEAU II}

Evolution des concentrations en quelques acides aminés libres du sang porte du porc au cours de la digestion du tournesol (en p. Ioo des concentrations du sang des animaux à jeun)

\begin{tabular}{|c|c|c|c|c|c|c|c|c|c|}
\hline & \multirow{2}{*}{ Régimes } & \multicolumn{8}{|c|}{ Temps apres le repas } \\
\hline & & $1 / 2 \mathrm{~h}$ & $1 \mathrm{~h}$ & $1 \mathrm{~h} 1 / 2$ & $2 \mathrm{~h}$ & 2 h $1 / 2$ & $3 \mathrm{~h}$ & $4 \mathrm{~h}$ & $5 \mathrm{~h}$ \\
\hline Nombre d'animaux & $\begin{array}{l}\mathrm{A} \\
\mathrm{B}\end{array}$ & $\begin{array}{l}3 \\
3\end{array}$ & $\begin{array}{l}2 \\
3\end{array}$ & $\begin{array}{l}3 \\
3\end{array}$ & $\begin{array}{l}1 \\
3\end{array}$ & $\begin{array}{l}3 \\
2\end{array}$ & $\begin{array}{l}1 \\
3\end{array}$ & $\begin{array}{l}2 \\
2\end{array}$ & $\begin{array}{l}3 \\
2\end{array}$ \\
\hline Nbre de prélèvements & $\begin{array}{l}\text { A } \\
\text { B }\end{array}$ & $\begin{array}{l}4 \\
4\end{array}$ & $\begin{array}{l}\text { 't } \\
5\end{array}$ & $\begin{array}{l}4 \\
3 \\
3\end{array}$ & $\begin{array}{l}3 \\
3\end{array}$ & $\begin{array}{l}4 \\
2\end{array}$ & $\begin{array}{l}3 \\
3\end{array}$ & $\frac{2}{3}$ & $\begin{array}{l}3 \\
2\end{array}$ \\
\hline Thréonine . & $\begin{array}{l}\text { A } \\
\text { B }\end{array}$ & $\begin{array}{l}155 \\
130\end{array}$ & $\begin{array}{l}214 \\
156\end{array}$ & $\begin{array}{l}189 \\
206\end{array}$ & $\begin{array}{l}220 \\
188\end{array}$ & $\begin{array}{l}170 \\
225\end{array}$ & $\begin{array}{l}149 \\
141\end{array}$ & $\begin{array}{r}163 \\
77\end{array}$ & $\begin{array}{r}101 \\
87\end{array}$ \\
\hline Citrulline & $\begin{array}{l}\mathrm{A} \\
\mathrm{B}\end{array}$ & $\begin{array}{r}120 \\
97\end{array}$ & $\begin{array}{l}162 \\
11^{\prime}\end{array}$ & $\begin{array}{l}177 \\
141\end{array}$ & $\begin{array}{l}156 \\
133\end{array}$ & $\begin{array}{l}181 \\
194\end{array}$ & $\begin{array}{l}134 \\
182\end{array}$ & $\begin{array}{r}165 \\
77\end{array}$ & $\begin{array}{l}100 \\
103\end{array}$ \\
\hline Proline . & $\begin{array}{l}\text { A } \\
\text { B }\end{array}$ & $\begin{array}{l}166 \\
130\end{array}$ & $\begin{array}{l}244^{\prime} \\
196\end{array}$ & $\begin{array}{l}174 \\
213\end{array}$ & $\begin{array}{l}252 \\
196\end{array}$ & $\begin{array}{l}205 \\
242\end{array}$ & $\begin{array}{l}187 \\
191\end{array}$ & $\begin{array}{r}135 \\
89\end{array}$ & $\begin{array}{l}130 \\
113\end{array}$ \\
\hline Glycine. & $\begin{array}{l}\mathrm{A} \\
\mathrm{B}\end{array}$ & $\begin{array}{l}82 \\
87\end{array}$ & $\begin{array}{l}132 \\
107\end{array}$ & $\begin{array}{r}97 \\
118\end{array}$ & $\begin{array}{l}127 \\
118\end{array}$ & $\begin{array}{l}116 \\
145\end{array}$ & $\begin{array}{l}113 \\
113\end{array}$ & $\begin{array}{r}1222 \\
63\end{array}$ & 92 \\
\hline Alanine & $\begin{array}{l}\text { A } \\
\text { B }\end{array}$ & $\begin{array}{l}150 \\
128\end{array}$ & $\begin{array}{l}232 \\
251\end{array}$ & $\begin{array}{l}176 \\
237\end{array}$ & $\begin{array}{l}246 \\
200\end{array}$ & $\begin{array}{l}171 \\
2 l_{1} 7\end{array}$ & $\begin{array}{l}176 \\
160\end{array}$ & $\begin{array}{r}163 \\
71\end{array}$ & $\begin{array}{r}116 \\
90\end{array}$ \\
\hline Valine ... & $\begin{array}{l}\text { A } \\
\text { B }\end{array}$ & $\begin{array}{r}112 \\
93\end{array}$ & $\begin{array}{l}172 \\
131\end{array}$ & $\begin{array}{l}138 \\
143\end{array}$ & $\begin{array}{l}165 \\
140\end{array}$ & $\begin{array}{l}130 \\
164\end{array}$ & $\begin{array}{l}137 \\
135\end{array}$ & $\begin{array}{r}147 \\
68\end{array}$ & $\begin{array}{l}94 \\
90\end{array}$ \\
\hline Isoleucine . & $\begin{array}{l}\mathrm{A} \\
\mathrm{B}\end{array}$ & $\begin{array}{l}142 \\
122\end{array}$ & $\begin{array}{l}211 \\
162\end{array}$ & $\begin{array}{l}165 \\
197\end{array}$ & $\begin{array}{l}208 \\
196\end{array}$ & $\begin{array}{l}155 \\
205\end{array}$ & $\begin{array}{l}16.3 \\
155\end{array}$ & $\begin{array}{r}170 \\
80\end{array}$ & $\begin{array}{r}118 \\
89\end{array}$ \\
\hline Leucine & $\begin{array}{l}\mathrm{A} \\
\mathrm{B}\end{array}$ & $\begin{array}{l}154 \\
140\end{array}$ & $\begin{array}{l}214 \\
168\end{array}$ & $\begin{array}{l}163 \\
211\end{array}$ & $\begin{array}{l}196 \\
186\end{array}$ & $\begin{array}{l}1 / 43 \\
204\end{array}$ & $\begin{array}{l}139 \\
132\end{array}$ & $\begin{array}{r}157 \\
64\end{array}$ & $\begin{array}{r}104 \\
80\end{array}$ \\
\hline Tyrosine & $\begin{array}{l}\text { A } \\
\text { B }\end{array}$ & $\begin{array}{l}189 \\
150\end{array}$ & $\begin{array}{l}2.23 \\
176\end{array}$ & $\begin{array}{l}186 \\
224\end{array}$ & $\begin{array}{l}233 \\
197\end{array}$ & $\begin{array}{l}184 \\
245\end{array}$ & $\begin{array}{l}139 \\
155\end{array}$ & $\begin{array}{r}180 \\
81\end{array}$ & $\begin{array}{r}105 \\
85\end{array}$ \\
\hline Phénylalanine & $\begin{array}{l}\mathrm{A} \\
\mathrm{B}\end{array}$ & $\begin{array}{l}195 \\
180\end{array}$ & $\begin{array}{l}275 \\
2 ! 7\end{array}$ & $\begin{array}{l}224 \\
296\end{array}$ & $\begin{array}{l}315 \\
257\end{array}$ & $\begin{array}{l}231 \\
332\end{array}$ & $\begin{array}{l}228 \\
188\end{array}$ & $\begin{array}{r}220 \\
83\end{array}$ & $\begin{array}{r}128 \\
88\end{array}$ \\
\hline Ornithine & $\begin{array}{l}\mathrm{A} \\
\mathrm{B}\end{array}$ & $\begin{array}{l}138 \\
120\end{array}$ & $\begin{array}{l}202 \\
145\end{array}$ & $\begin{array}{l}176 \\
202\end{array}$ & $\begin{array}{l}185 \\
154\end{array}$ & $\begin{array}{l}152 \\
198\end{array}$ & $\begin{array}{l}147 \\
147\end{array}$ & $\begin{array}{r}157 \\
80\end{array}$ & $\begin{array}{l}98 \\
92\end{array}$ \\
\hline Lysine & $\begin{array}{l}\mathrm{A} \\
\mathrm{B}\end{array}$ & $\begin{array}{l}171 \\
125\end{array}$ & $\begin{array}{l}217 \\
161\end{array}$ & $\begin{array}{l}194 \\
155\end{array}$ & $\begin{array}{l}170 \\
133\end{array}$ & $\begin{array}{l}186 \\
132\end{array}$ & $\begin{array}{r}142 \\
91\end{array}$ & $\begin{array}{r}143 \\
62\end{array}$ & $\begin{array}{r}108 \\
67\end{array}$ \\
\hline Histidine. & $\begin{array}{l}\mathrm{A} \\
\mathrm{B}\end{array}$ & $\begin{array}{l}151 \\
128\end{array}$ & $\begin{array}{l}188 \\
146\end{array}$ & $\begin{array}{l}160 \\
196\end{array}$ & $\begin{array}{l}195 \\
170\end{array}$ & $\begin{array}{l}169 \\
198\end{array}$ & $\begin{array}{l}147 \\
136\end{array}$ & $\begin{array}{r}167 \\
74\end{array}$ & $\begin{array}{r}134 \\
82\end{array}$ \\
\hline
\end{tabular}

Régime A : tournesol supplémenté en lysine.

Régime B : tournesol non supplémenté en lysine.

Pion, Rérat, (1969). 
Les variations de concentrations observées dans le cas des acides aminés non indispensables n'ont souvent que peu de lien avec la composition de l'aliment :

- les augmentations des teneurs en glycine et en alanine sont très importantes comparées aux apports alimentaires, alors que l'acide aspartique et la somme glutamine + acide glutamique n'augmentent que relativement peu. Ces faits sont probablement dus à des métabolisations dans la muqueuse intestinale ; il en est de même pour l'élévation de la teneur du sang porte en ornithine, après ingestion d'arachide, riche en arginine.

Nous avons étudié ensuite (PION et RéRAT, 1967) la supplémentation blé-acides aminés libres. Les repas expérimentaux étaients constitués, soit du régime de base dont la seule source de protéine était le blé riche en azote et supplémenté en lysine et en tryptophane, soit du même régime non supplémenté. Les proportions des différents acides aminés indispensables dans le sang prélevé au début du repas sont voisines de celles qui avaient été observées précédemment (tabl. 7) ; après ingestion de l'aliment supplémenté en lysine, les concentrations des acides indispensables du sang porte augmentent très vite, ce qui est probablement lié à une vidange stomacale rapide, puis diminuent 2 heures après le début du repas (tabl. 1o). Le maximum observé pour la lysine est beaucoup plus faible lorsque la ration ne comporte pas de lysine libre, et les concentrations des autres acides aminés restent élevées pendant plusieurs heures après l'ingestion des repas non supplémentés, probablement parce que leur utilisation est limitée par l'absence de lysine.

Enfin, nous avons étudié (Pıon et RÉRAT, 1969) la supplémentation en lysine d'un aliment protéique bien différent du précédent : le tourteau de tournesol, supplémenté en méthionine et en tryptophane. La cinétique de l'évolution des concentrations en acides aminés du sang porte est voisine de celle qui avait été observée dans le cas du blé (tabl. I I). Les différences observées reflètent généralement la composition des régimes en ce qui concerne les acides aminés indispensables : lysine, thréonine, isoleucine en particulier, et sont amplifiées dans le cas de la lysine. Toutefois les variations de teneur $d u$ sang porte en tyrosine et phénylalanine sont beaucoup plus faibles dans le cas du tournesol, quoique les apports alimentaires soient voisins, ce qui peut avoir deux causes : ou bien l'utilisation n'est pas totale (digestion et absorption), ou bien le tube digestif en prélève une plus grande quantité pour effectuer des synthèses rendues permises par la présence

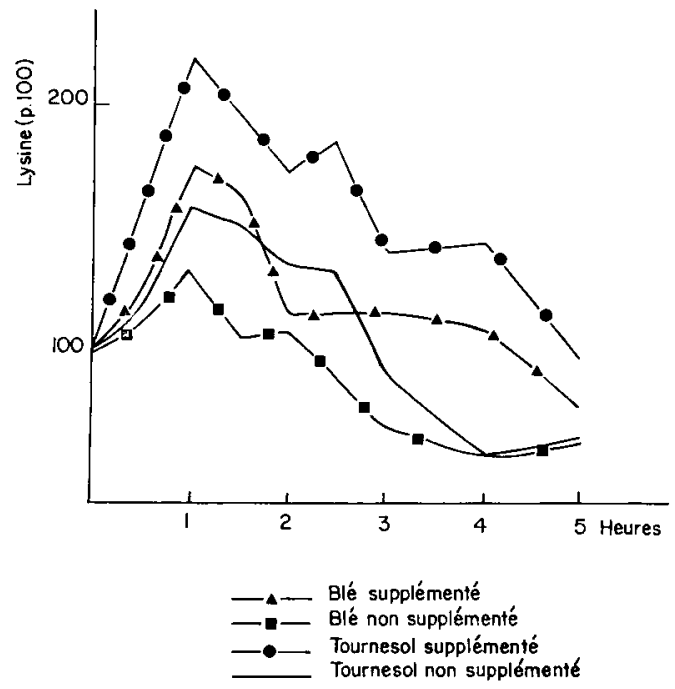

FiG. I. - Concentration de la lysine libre dans le sang porte pendant la digestion (p. Ioo de la concentration au début du repas)

(Pion et Rérat, i969) 
en plus fortes proportions des autres acides aminés. La lysine supplémentaire semble être absorbée à la même vitesse que celle qui provient des protéines aussi bien dans le cas du blé que dans celui du tournesol (fig. I).

L'ensemble de ces expériences montre que la composition du mélange d'acides aminés qui apparaît dans la veine porte au cours de la digestion peut varier dans de très larges proportions en fonction de la composition des protéines alimentaires. Aussi, cette méthode d'étude doit-elle se prêter aussi bien à l'étude des supplémentations qu'à celle de l'indisponibilité de certains acides aminés liée à une libération imparfaite, ou trop lente. Elle devrait être complétée par une étude de la vidange stomacale qui comporte généralement deux phases (AUFFrAy et al., 1967) et qui constitue le premier facteur de la cinétique de la digestion.

\section{VALEUR NUTRITIVE DES PROTÉINES}

La ration consommée doit contenir chaque jour la quantité d'acides aminés indispensables nécessaires à la protéinogenèse permise par le potentiel génétique des animaux. La valeur nutritive des protéines alimentaires dépend essentiellement des quantités des divers acides aminés indispensables constitutifs. Les diverses protéines d'une ration constituent un spectre d'acides aminés indispensables plus ou moins différents du spectre idéal défini par les besoins (tabl. I2). Il est

\section{TABLEAU I 2}

Comparaison des acides aminés indispensables et semi-indispensables de différents aliments avec les besoins du porc

(en p. roo de la somme de ceux-ci)

\begin{tabular}{|c|c|c|c|c|c|c|c|c|c|}
\hline & Orge & Blé & Maîs & Soja & $\begin{array}{l}\text { Ara- } \\
\text { chide }\end{array}$ & $\begin{array}{l}\text { Tour- } \\
\text { nesol }\end{array}$ & Euf & $\begin{array}{c}\text { Farine } \\
\text { de } \\
\text { hareng }\end{array}$ & $\begin{array}{l}\text { Besoins } \\
\text { du porc }\end{array}$ \\
\hline Thréonine. & 9,6 & 8,8 & 10,2 & 9,4 & 8,6 & 9,65 & 9,5 & 9,65 & 10,25 \\
\hline Valine $\ldots \ldots \ldots \ldots$ & 15,15 & 14,75 & 14,55 & 12,75 & 15,0 & 15,05 & 13,85 & 12,8 & 10,0 \\
\hline Isoleucine $\ldots \ldots \ldots$ & 10,7 & 11,55 & 10,65 & 11,85 & 11,85 & 12,3 & 10,75 & 10,55 & 11,5 \\
\hline $\begin{array}{l}\text { Leucine } \ldots \ldots \ldots \ldots \\
\text { Tyrosine }\end{array}$ & 16,05 & 17,35 & 15,95 & 18,3 & 17,8 & 16,8 & 16,1 & 15,85 & 13,7 \\
\hline $\left.\begin{array}{c}\text { Phényl- } \\
\text { alanine }\end{array}\right\} \cdots \cdots \cdots$ & 12,2 & 12,2 & 12,15 & 11,85 & 12,6 & 11,95 & 12,0 & 11,85 & 12,0 \\
\hline $\left.\begin{array}{l}\text { Méthionine } \\
\text { Cystine }\end{array}\right\}$ & 12,25 & 12,15 & 12,65 & 6,75 & 7,8 & 10,9 & 11,4 & 8,9 & 12,6 \\
\hline Lysine & 10,15 & 8,5 & 8,75 & 15,35 & 10,6 & 9,5 & 14,25 & 18,45 & 16,5 \\
\hline Histidine. & 5,75 & 6,7 & 7,65 & 6,4 & 7,35 & 6,6 & 4,65 & 4,7 & 4,8 \\
\hline Arginine. . & 7,4 & 7,4 & 7,45 & 7,2 & 7,6 & 7,25 & 7,0 & 7,2 & 6,0 \\
\hline $\begin{array}{l}\text { Somme des AAI } \ldots \\
\text { équilibrés } \mathrm{g} / 16 \mathrm{~g} \mathrm{~N}\end{array}$ & 35,9 & 32,9 & 37,2 & 43,0 & 32,0 & 37,85 & 52,65 & 44,45 & $\begin{array}{c}2,6 \\
\text { trypto. }\end{array}$ \\
\hline
\end{tabular}

Leucine limitée à 150 p. 100 d'isoleucine.

Arginine limitée à 7,3 p. 100 environ du total des acides aminés.

Tyrosine + phénylalanine limitée à 12 p. 100 environ du total.

En chiffres gras: déficience importante (> 20 p. 100).

En chiffres italiques: déficience faible. 
possible, en exprimant les différents acides aminés indispensables des protéines alimentaires en p. too de leur somme, de comparer les diverses protéines et d'utiliser au mieux leurs possibilités de supplémentation.

La réalisation de rations contenant les différents acides aminés indispensables en proportions équilibrées est facilitée par l'amélioration de la qualité de certaines protéines (mais), l'utilisation d'acides aminés industriels et de nouvelles sources de protéines (levure).

\section{Amélioration de la qualité des céréales}

Les céréales, et le maïs en particulier, sont pauvres en lysine et aussi en tryptophanequi peut être apporté en quantité appréciable par la farine de luzerne $(\mathrm{I}, 7 \mathrm{~g} / \mathrm{1} 6 \mathrm{~g}$ N) (Hintz et HeITMAN, 1967). Un maïs contenant ro p. Ioo de protéines, supplémenté en lysine et en tryptophane peut assurer le besoin en acides aminés indispensables du porc après $50 \mathrm{~kg}$ mais ne peut assurer la croissance normale du jeune porc. Certains acides aminés indispensables tels que l'isoleucine et la valine y seraient partiellement indisponibles (Gallo et POND, I968; Gallo et al., I968; VerMOREL, I969).

De nouvelles variétés de maïs ont été obtenues grâce à des mutants Opaque 2 et Farineux 2 aux U. S. A. (Nielson. 1965) et Amylose extender en France (Baudet et al., 1968). Ces mutants ont des protéines pauvres en zéine et sont mieux équilibrés en lysine $(3,5-5,0$ contre $2,6 \mathrm{~g} / \mathrm{I} 6 \mathrm{~g} \mathrm{~N})$ et en tryptophane. En outre, il semble que la disponibilité des acides aminés indispensables de ces maïs soit meilleure (CROMWELL et al, I967).

\section{Produits industriels}

L'utilisation d'acides aminés libres produits industriellement se développe depuis une dizaine d'années. Elle a fait l'objet d'études récentes chez le porc (Hintz et Heitman, 1967, Jurgens et al., I967; Rérat et Henry, 1969). La DL-méthionine est utilisée couramment et permet de supplémenter les rations déficientes en cet acide aminé. La méthionine est en général correctement utilisée, mais des études plus fines comportant une meilleure connaissance des besoins, l'analyse de la vidange stomacale de la méthionine et des protéines alimentaires et la mesure de l'aminoacidémie porte seraient nécessaires. La L-lysine est souvent trop conteuse pour concurrencer le soja (au prix international) dans la supplémentation des céréales. En outre, les protéines d'origine industrielle (levures) produites sur les đérivés du pétrole sont riches en lysine $(5,5-9 \mathrm{p} .100 \mathrm{~g} / \mathrm{l} 6 \mathrm{~g} \mathrm{~N})$ et peuvent ainsi suppléer à la déficience en lysine des céréales et concurrencer la L-lysine industrielle.

\section{Influence des traitements technologiques et disponibilité des acides aminés}

Les traitements technologiques sont de plus en plus utilisés pour la conservation des aliments (séchage artificiel des céréales) et pour leur utilisation (délipidation des graines oléagineuses). En outre, les traitements technologiques permettent l'obtention de produits (et sous-produits) destinés à des fabrications de plus en plus diversifiées : les farines riches en protéines obtenues par turboséparation sont destinées aux animaux. A ces fabrications s'ajoute la conservation destinée à amortir les variations annuelles de productions. Tous ces facteurs peuvent contribuer à modifier sinon la composition en acides aminés indispensables des protéines, du moins leur disponibilité

Il est actuellement possible de mesurer avec précision les teneurs en acides aminés indispensables des rations, et l'analyse de leur disponibilité dans les protéines (végétales en particulier) peut enfin être abordée. Le Rat a en général été utilisé pour ces études; le blé paraît avoir des protéines dont la lysine et la thréonine sont parfaitement disponibles (PAWLAK et PION, 1968). Quelques travaux ont été amorcés chez le Porc : BaBcock et MarkLey (1967), ont montré quele gluten avait des acides aminés indispensables relativement peu disponibles (valine, isoleucine), 
en comparaison avec ceux des protéines du lait. Ce phénomène pourrait être lié au déséquilibre des divers acides aminés indispensables du gluten.

Wiesem Üller et Poppe (r969) ont entrepris une étude systématique de la valeur nutritive des protéines végétales et animales chez le porc de 25 à $35 \mathrm{~kg}$. Ces auteurs ont déterminé l'azote endogène intestinal excrété dans les fèces : $0,157 \mathrm{~g}$ d' $N$ par ıoo $\mathrm{g}$ de matières sèches ingérées, (MSI) ce qui correspond à environ I g de protéines par roo g de MSI. Cette détermination leur a permis de mesurer la digestibilité vraie des diverses protéines : 90 à Ioo p. Ioo ; une digestibilité vraie de 75 p. Ioo a été trouvée pour une orge, une levure et une farine de poisson ; il y a lieu d'examiner les traitements subis par ces produits qui entraînent une telle diminution de la digestibilité réelle de leurs protéines.

Les critères utilisés par WIESEMÜLLER et POPPE : azote fixé maximum, rendement maximum de l'azote ingéré etc. ne sont pas suffisants pour caractériser une protéine donnée. La valeur nutritive d'une protéine alimentaire dépend de sa capacité à mesurer les besoins en acides aminés indispensables de l'animal (WIEsemưtLler et Poppe, 1969); cette estimation nécessite l'utilisation de rations parfaitement équilibrées en acides aminés indispensables associées à une méthode de mesure de la disponibilité en ces acides aminés.

\section{CONCLUSION}

Les performances zootechniques doivent être analysées en terme d'azote fixé dans l'animal entier, ou mieux, dans les fractions consommables des carcasses : tissu musculaire et organe (Gallo et Pond, rg68).

Les besoins en acides aminés indispensables du porc doivent être précisés en utilisant des rations synthétiques, en particulier chez le jeune pendant la phase de fixation protéique intense, et exprimés par rapport à l'énergie digestible ou métabolisable. Les critères employés devraient comporter des bilans azotés associés à l'analyse fine de l'état de satisfaction des besoins en chacun des principaux acides aminés indispensables; la satisfaction de ces besoins est déterminée par la mesure des concentrations en acides aminés libres du sang et si possible du muscle, et par une programmation de l'apport alimentaire au cours de la journée (DEAN et Scotr, 1965, chez le Poulet). L'étude des enzymes du foie et du sérum pourrait permettre d'apprécier l'état de nutrition azotée global des animaux (BERGNer et al., 1966; TUMBLEson et LEADE, 1966).

L'étude de la disponibilité des diverses protéines alimentaires doit être entreprise sur les diverses espèces et en particulier chez le Porc. Des études préalables sur le Rat doivent permettre d'étudier les phénomènes spécifiques au porc liés à la cinétique de la vidange stomacale, du transport des acides aminés, à sa vitesse de croissance et à la composition particulière de son croit.

Reçu pour publication en janvier 1972.

\section{SUMMARY}

\section{SOME RECENT ASPECTS OF PROTEIN METABOLISM \\ AND THEIR CONSEQUENCES AS REGARDS THE SATISFACTION OF PROTEIN REQUIREMENTS IN THE PIG}

Several factors of the protein nutrition have been studied.

Growth and requirements for protein and amino acids (tables $\mathbf{I}-6$ )

Newborn pig bodies contain only I I p. Ioo protein and 6 p. Ioo lipids. After two weeks, they contain about I $5 \mathrm{p}$. Ioo protein and $16 \mathrm{p}$. Ioo lipids. Daily net body protein synthesis increases up to IOO- $125 \mathrm{~g} /$ day for pigs weighing 30 to $35 \mathrm{~kg}$. For older pigs, it remains fairly constant 
whereas the lipid synthesis increases all the more as the feeding level gets higher. Protein synthesis, is not reduced by an energy restriction corresponding to $15-20 \mathrm{p}$. roo of the requirement. The bound protein/metabolizable energy ratio remains constant up to $35-40 \mathrm{~kg}$ live weight. and then decreases when the animals grow larger. Consequently, the protein/metabolizable energy ratio (or protein/digestible energy ratio) of the diet has to remain constant in the first growth period, and must be reduced in the second period when the animals grow in age.

Changes in the requirements during growth are not identical for all essential amino acids. Daily lysine need increases fastly up to $4^{\circ} \mathrm{kg}$ live weight, and then more slowly. The increase in the second growth period is only related to a higher requirement for maintenance. On the contrary, the need for methionine is increasing faster with age than the mean amino acid requirement (table 6).

The accuracy in the determinations of amino acid needs is improving each year, as it may be seen from the comparison of the needs of different animal species.

\section{Free amino acids in the blood and protein nutrition}

Products of digestion of dietary proteins are carried to the sites of protein synthesis mainly as free amino acids in the blood plasma. Their contents depend, at any moment, on the balance between the amino acids coming from the digestive tract or resulting from the catabolism of body protein, and those used for protein synthesis. Therefore, many research workers have looked for a connection between free amino acids in pig blood, amino acid needs and dietary amino acids. Mean values from different studies generally agree as far as essential amino acids are concerned (table 7). There is an interrelationship between the contents of the different amino acids, but those of the essential amino acids are generally related to the amino acid composition of the diet.

\section{Free amino acids in the blood and protein digestion}

The concentrations of the different free amino acids in the portal blood depend on their rates of release by the digestive tract. Therefore, we studied the variations in the portal amino acid contents during digestion of various feeds : herring meal, barley meal, peanut meal, protein free meal, wheat and sunflower meal with or without addition of free lysine. Increases in the essential amino acid contents were very high for herring meal and very small for barley.

They were high during the course of peanut digestion, except for lysine and threonine which are the limiting factors of that protein feed. Free lysine seems to be absorbed at the same rate as lysine coming from the digestion of sunflower or wheat proteins (tables Io, I 1, fig. r). Since the variations of the free amino acid concentrations were very large during digestion, their determination may be useful when studying the protein and amino acid supplementation and the availability of some amino acids.

\section{Nutritive value of proteins}

The proportions of the different amino acids in the dietary proteins correspond more or less to the requirements of the animals (table 12 ). The compositions of the various feeds can easily be compared the one with the others and with the requirements of the animals by expressing the contents of every essential and semi essential amino acid as a p. roo of their total amount. The design of well balanced diets is becoming easier because of the improvement of some proteins (maize) and the use of industrial amino acids (DL-methionine, L-lysine) and proteins (yeasts, alga). However, the availability of some amino acids may be reduced during the course of processing or during storage, and there is more and more need for an accurate technique for measuring this availability.

\section{RÉFÉRENCES BIBLIOGRAPHIQUES}

Agricultural Research Council, I967. The mutrient of farm livestock, no 3 , Pigs, London.

Anderson G. H., Bowland J. P., I967. Lysine and fat supplementation of weanling pig diets. Can. J. Anim. Sci., 47, 47-55.

Auffray P., Martinet J., Rérat A., r967. Quelques aspects du transit gastro-intestinal chez le porc. Ann. Biol. anim. Bioch. Biophys., 7, 261-279.

BABCOCK M. J., MARKLEY R. A., I967. Utilization of amino acids from protein by weanling pigs. $J$. Nutr., 93, 368-376. 
Baker D. H., Becker D. E., Norton H. W., Jensen A. H., Harmon B. G., Ig66 a. Some qualitative amino acid needs of adult swine for maintenance. J. Nutr., 88, 382-390.

Baker D. H., Becker D. E., Norton H. W., Jensen A. H., Harmon B. G., rg66 $b$. Quantitative evaluation of the threonine isoleucine, valine and phenylalanine needs of adult swine for maintenance. J. Nutr., 88, 39I-396.

Baker D. H., Becker D. E., Norton H. W., Jensen A. H., Harmon B. G., ig66 c. Quantitative evaluation of the tryptophan, methionine and lysine needs of adult swine for maintenance. J.Nutr., 89, 44I-447.

Baudet J., Cauderon A., Fauconneau G., Mosse J., Pion R., Ig68. Sur un troisième gène mutant (amylose extender) qui accroît la teneur en lysine du grain de maïs et sur son effet cumulatif avec le gène opaque 2. C. R. Acad. Sci., 266, 2260-2263.

Becker D. E., Jensen A. H., Harmon B. G., r963. III. Agr. Exp. Sta. Circ., no 866.

Berge S., INDReb $\emptyset$ T., 1954. Composition of body and weight gain of suckling pigs. Meld. Norg. Landbruks, 34, 481-500.

Bergner H., Wirthgen B., Munchow H., ig66. Protein in feedingstuffs I-glutamate oxaloacetate transaminase, glutamate pyruvate transaminase and ornithine carbamothyltransferase in serum of pigs fed on protein of whole egg, barley or different yeasts or on a protein free diet. Arch. Tierernähr., 16, 507 .

Boaz T. G., Elsley F. W. H., 1962. The growth and carcass quality of bacon pigs reared to different weights at 56 days old. Anim. Prod., 4, 13-24.

Chance R. E., r962. In Amino acid requirements of salmon. These Purdue Univ. Ph. (D), 68-I8r.

Clawson A. J., I967. Influence of protein level amino acid ratio and caloric density of the diet on feed intake and performance of pigs. J. Anim. Sci., 26, 328-334.

Combs G. E., Conness R. G., Berry T. H., Wallace H. D., Ig67. Effect of raw and heated soybeans on gain, nutrient digestibility, plasma amino acids and other blood constituents of growing pigs. J. Anim. Sci., 26, 1067-1071.

Cooke R., Lodge G. A., Lewis D., 1966. Nitrogen balance and plasma amino acids in the pig. Proc. 9th Intern. Cong. Anim. Proc., Edinburgh, 124- 29 .

Cromwell G. L., Cline T. R., Pickett R. A., Beeson W. M., 1967. Growth and nitrogen balance studies with "opaque-2 corn. J. Anim. Sci., 26, 905-912.

Cuperlovic M., r967. Free amino acids in the blood plasma of newborn piglets before and after the first intake of colostrum. Acta Vet. Scand., 8, 217-227.

Čuperlovic M., Jovanovic M., Stosic D., I968. Proc. Int. Symp., Vienne, 193.

Dean W. F., Scort H. M., x965. The development of an amino acid reference diet for the early growth of chicks. Poulty, Sci., 44, 803-808.

Durand G., Fauconneau G., Penot E., I967a. Évolution des teneurs en acides nucléiques et en protéines du foie du porc au cours de la croissance postnatale. Bull. Soc. Chim. Biol., 49, 36I-370.

Durand G., Fauconneau G., Penot E., r967 $b$. Évolution de la teneur en acides nucléiques et en protéines du muscle chez le porc au cours de la croissance postnatale. C. $R$. Acad. Sc. (D), 264, I640I643.

Durand G., Penot E., I97o. Effets du maintien à poids constant pendant de longues durées chez le rat sevré. Reprise de la croissance. Ann. Biol. anim. Bioch. Biophys., 10, 385-400.

ELSLEY F. W. H., I963. Studies on growth and development in the young pig. part II. A comparison of the performance to $200 \mathrm{lb}$ of pigs reared along different growth curves to 56 days of age. J.A gric. Sci., 61, 243-25r.

Farries E., Angelowa L., Schroder J., I968. Digestibility of nutrient and $N$ retention in Pietrain pigs 2-retention and utilisation of $\mathrm{N}$ in relation to growth. Ztschr. Tierphysiol. Tierernähr. Futtermittelk., 23, 340-349.

Fauconneau G., I966. Quelques aspects actuels de la nutrition azotée des animaux monogastriques. Proc. 9th Intern. Cong. Anim. Prod., Edinburgh, 46-59.

TENDER M., 1968. Schweinemastversuch mit gestaffelten Aminosäurengehalt in linear programmierten Futtermischungen. Ztsch. Tierphysiol. Tierernähr. Futtermittelk., 24, 257-263.

Gallo J. T., Pond W. G., I968. Amino acid supplementation to all corn diets for pigs. J.Anim. Sci., 27, $73-78$.

Gallo J. T., Pond W. G., Logomarsino J. V., i968. Response of early weaned pigs to amino acid supplementation of corn diets. J.Anim. Sci., 27, I ooo-I oo5.

Gruns K., 1965. Einfluss der Alters auf Nährstoffgehalt und Fleischeiweisszusammensetzung bei Schweinen. Nahrung, 9, 325-333.

Henk G., Laube W., I967. Experiments studying the effects of feeding intensity upon the growth rate, feed consumption, energy utilisation and protein retention in fattening pigs. Arch. Tierernähr., 17, 393-407.

HeNRY Y., I968. Libre consommation de principes énergétiques et azotés chez le rat et chez le porc selon la nature de la source azotée, sa concentration dans le régime et le mode de présentation. Amn. Nutr. Alim. 22, r2 I-r 40. 
Hintz H. F., Heitman H., I967. Amino acid and vitamin supplementation to barley cottonseed meal diets for growing-finishing swine. J. Anim. Sci., 26, 474-478.

Homb T., Matre T., r967. Protein and amino acids requirements of growing finishing pigs in Norway. Ztschr. Tierphysiol. Tierernähr. Futtermittelk., 23, I29-I42.

Hornicke H., I96I. Methods of estimating body composition of living animals with special reference to pigs. 4. Bases for calculation of body composition in the pig. Ztschr. Tierphysiol. Tierernähr. Futtermittelk., 16, 344-366.

Jurgens M. H., Hudman D. B., Adams C. H., Peo E. R., I967. Influence of a dietary supplement of lysine fed at two levels of protein on growth feed efficiency and carcass caracteristics of swine. $J$. Anim. Sci., 26, 323-327.

Krysciak J., Ostrowski H., Rys R,, 1966. Changes in the content of free amino acids in pig blood plasma after ingestion of food. Acta. Biochim. Polon., 13, 229-235.

LODGE G. A., 1962. In Nutrition of pigs and poultry, Éd. Morgan J. T. et Lewis D., London, Butterworths, 224-237.

LoNG J. E., HAYS V. W., Speer V. C., 1965. Effect of supplemental amino acids on growth and plasma amino acids concentrations of pigs. J. Anim. Sci., 24, 894-907.

Lucas I. A. M., r962. In Nutrition of pigs and poultry, Ed. Morgan J. T. and Lewis D., London, Butterworths, 238-253.

Manners M. J., McCrea M. R., I963. Changes in the chemical composition of sow reared piglets during the ist month of life. Br. J. Nutr., 17, 495-5 I3.

Mitchell J. R., 1965. Effect of level of amino acid intake on the nitrogen metabolism and plasma free amino acids of the young pig. These Univ. Illinois $\mathrm{Ph}$ (D).

Mitchell J. R., Becker D. E., Jensen A. A., Harmon B. G., Norton H. W., ig64. Amino acid needs of the young pig fed a semi-synthetic diet. J. Anim. Sci., 23, I2 I5.

Mitchell J. R., Becker D. E., Jensen A. H., Harmon B. G., Norton H. W., I964. Potential of plasma free amino acids as a criterion of dietary need for certain amino acids. J. Anim. Sci., 23, $12 \mathrm{I} 6$.

Mitchell J. R., Becker D. E., Harmon B. G., Norton H. W., Jensen A. H., ig68. Some amino acid needs of the young pig fed a semisynthetic diet. J. Anim. Sci, 27, 1322-1 326.

Mitchell J. R. Jr, Becker D. E., Jensen A. H., Harmon B. G., Norton H. W., ig68. Determination of amino acid needs of the young pig by nitrogen balance and plasma free amino acid. $J$. Anim. Sci., 27, I327-I331.

Navratil B., Simeneck K., I963. Supplementation of pig feeds with L-lysine and DL-methionine. Ziroc. Vyr., 8, 575-584. See. Nutr. Abstr. Rev. 1964, 34, no 3343 .

Nielson C., r 965 . Second mutant gene affecting the amino acid pattern of maize endosperm protein. Sci., 150, I469-I 476.

N. R. C. (National Research Council), ig68. Nutrient requirements of swine publ. I599, National Academy of Sciences, Washington D. C.

Oslage H. J., Fliegel, H., I964. In Energy metabolism. Ed. Blaxter K. L., Proc. 3th Symp. Troon. Acad Press, 297-306.

Pawlak M., PION R., I968. Influence de la supplémentation des protéines de blé par des doses croissantes de lysine sur la teneur en acides aminés libres du sang et du muscle du rat en croissance. Ann. Biol. anim. Bioch. Biophys., 8, 517-530.

Pick R. I., MEAde R. J., I968. Availability to growing swine of lysine and isoleucine from high lysine corn. J. Anim. Sci., 47, I 778 .

Pion R., De Belsunce C., Fauconneau G., I963. Composition en acides aminés de quelques aliments. Ann. Biol. anim. Bioch. Biophys., 3 (h. s. I), 11-23.

PioN R., I965. Données personnelles.

Pion R., Fauconneau G., I968. In Munro H. N. : Mammalian protein metabolism, vol. 3, 508. Academic Press, New York, London.

Pron R., Fauconneav G., Rérat A., I964. Variation de la composition en acides aminés du sang porte au cours de la digestion chez le porc. Ann. Biol. anim. Bioch., Biophys., 4, 383-40r.

Pion R., Rérat A., I967. Influence d'une supplémentation en lysine sur l'évolution de l'aminoacidémie porte du porc en croissance au cours de la digestion d'une ration à base de blé. C. R. Acad. Sci. 264, $632-635$.

ProN R., RÉrat A., I969. Influence de la supplémentation en lysine des protéines du tournesol sur l'aminoacidémie porte du porc au cours de la digestion. Journées de la recherche porcine en France, I. N. R. A., Paris, 15 I-156.

Poppe S., Wiesemuller W., I968. Studies on the amino acid requirements of growing pigs. I. Determination of lysine requirements in nitrogen balance tests. Arch. Tierernähr., 18, 392-403.

Puchal F., Hays V. W., Speer V. C., Jones J. D., Catron D. V., I962. The free blood plasma amino acids of swine as related to the source of dietary proteins. J. Nutr., 76, I I-I6.

Ranhotra G. S., Johnson B. C., I965. Effect of feeding different amino acid diets on growth rate nitrogen retention of weanling rats. Soc. Exp. Biol. Med., 118, r I97-1201.

Rérat A., Henry Y., I967. Étude de besoin azoté chez le porc en croissance. II. Utilisation de la 
farine de poisson à des doses excessives par rapport au besoin azoté. Ann. Zootech., 16, 203-211. Rérat A., Henri Y., I969. (Communication personnelle).

Rérat A., Lougnon J., xg66. In Amino acides, peptides, protêines cahier no 6. Alimentation Équilibrée, Commentry, 34I-422.

Richardson L. R., Cannon M. L., Webb B. D., 1965. Relation in dietary protein and lysine to free amino acids in chick tissues. Poultry Sci., 44, 248-257.

Rippel R. H., I967. Protein and amino acid nutrition of gravid swine. J. Anim. Sci., 26, 526-532.

Salmon-Legagneur, 1965. Quelques aspects des relations nutritionnelles entre la gestation et la lactation chez la truie. Ann. Zootech., 14 HS I, I37.

Spolter P. D., Harper A. E., I96r. Leucine isoleucine antagonism in the rat. Am. J. Physiol., 200, 5 × $3-5$ I 8 .

Strunz K., Lenkeit W., I963. Die Stickstoff und Nucleinsäure Verteilung in Ferkelkörper unter dem Einfluss der Proteinzufuhr (vorläufige Ergebnisse) 2. DNS und RNS Gehalt in Skeletmusculatur, Herzmusculatur, Niere, Leber und Milz. Ztschr. Tierphysiol. Tierernähr. Futtermittelk. 18, 285-340.

Тноввек G., I968. In : Energy metabolism of farm animals, Proc. $4^{\text {th }}$ Symposium Warsaw 1967. Ed. Blaxter K. L., Kielanowski J., Thorbek G., Oriel Press 281-289.

Tumbleson M. E., Meade R. J., I966. Effect of source and level of dietary protein on liver enzyme systems in the young pig. J. Nutr., 89, $487-494$.

Typpo J. T., Meade R. J., I964. Effect of time of fast on plasma free amino acids in the growing pig. J. Anim. Sci., 23, I220.

VERMOREL M., I969. Utilisation énergétique par le rat en croissance d'un maïs hybride "opaque 2 " composant un régime équilibré en acides aminés. C. $R$. Acad. Sc., Paris, 268, 834-837.

Wiesemulter W., Poppe S., ig68. Studies on the amino acids requirements of growing pigs. 2. Estimation of requirements for sulfur. Arch. Tierernähr., 18, 405-4I5.

Wiesemuller W., Poppe S., I969. Estimation of protein by determining the N balance. 4. Methods for conducting $\mathrm{N}$ balance studies on pigs receiving varying levels of protein. Arch. Tierernähr., 19, I $32-147$.

Wiesemuller W., Poppe S., 1969. Estimation of proteins by determinng the N balance. 5. determination of true digestibility in N-balance trials with rations containing varying protein levels. $A r c h$. Tierernähr., 19, I 49 -I 56 .

Wiesemuller W., Poppe S., 1969. Biological value of some dietary proteins for pigs I-N-balance trials on pigs receiving varying amount of vegetable proteins. Arch. Tierernähr., 19, I57-169.

Wiesemuller W., Poppe S., I969. Biological value of some dietary proteins for pigs. 2. N-balance trials on pigs receiving varying levels of animal protein sources. Arch. Tierernähr., 19, I7I-I85.

Williams H. H., Curtin L. V., Abrainam J., Loosli J. K., Maynard L. A., ig64. Estimation of growth requirements for amino acids by essay of the carcass. J. Biol. Chem., 208, $277-286$. 